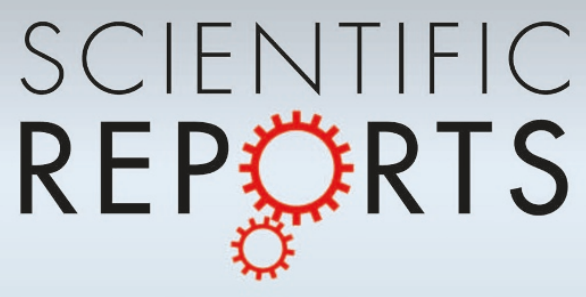

OPEN

SUBJECT AREAS:

ADULT STEM CELLS

HAEMATOPOIETIC STEM CELLS

Received

19 September 2013

Accepted

16 May 2014

Published

6 June 2014

Correspondence and requests for materials should be addressed to

R.J. (rjurecic@med. miami.edu)

* These authors contributed equally to this work.

\title{
Dynamic equilibrium of heterogeneous and interconvertible multipotent hematopoietic cell subsets
}

\author{
Wendy Weston ${ }^{2 *}$, Jennifer Zayas ${ }^{1 *}$, Ruben Perez' ${ }^{1}$ John George' \& Roland Jurecic ${ }^{1,2}$
}

\begin{abstract}
'Department of Microbiology and Immunology, Miller School of Medicine, University of Miami, Miami, FL 33136, USA,
${ }^{2}$ Department of Cell Biology, Miller School of Medicine, University of Miami, Miami, FL 33136, USA.
\end{abstract}

Populations of hematopoietic stem cells and progenitors are quite heterogeneous and consist of multiple cell subsets with distinct phenotypic and functional characteristics. Some of these subsets also appear to be interconvertible and oscillate between functionally distinct states. The multipotent hematopoietic cell line EML has emerged as a unique model to study the heterogeneity and interconvertibility of multipotent hematopoietic cells. Here we describe extensive phenotypic and functional heterogeneity of EML cells which stems from the coexistence of multiple cell subsets. Each of these subsets is phenotypically and functionally heterogeneous, and displays distinct multilineage differentiation potential, cell cycle profile, proliferation kinetics, and expression pattern of HSC markers and some of the key lineage-associated transcription factors. Analysis of their maintenance revealed that on a population level all EML cell subsets exhibit cell-autonomous interconvertible properties, with the capacity to generate all other subsets and re-establish complete parental EML cell population. Moreover, all EML cell subsets generated during multiple cell generations maintain their distinct phenotypic and functional signatures and interconvertible properties. The model of EML cell line suggests that interconvertible multipotent hematopoietic cell subsets coexist in a homeostatically maintained dynamic equilibrium which is regulated by currently unknown cell-intrinsic mechanisms.

$\mathrm{N}$ umerous studies have established phenotypic and functional heterogeneity within populations of embryonic stem (ES) cells, adult neural, intestinal and hematopoietic stem cells (HSCs) and cancer stem cells (CSCs), which arises from the coexistence of different stem cell subsets ${ }^{1-18}$. Moreover, a number of studies reported the existence of interconvertible cell subsets among ES cells, intestinal stem cells and HSCs, which oscillate between several metastable states, as well as bidirectional interconversions between mammary and intestinal CSCs and non-CSCs ${ }^{19-28}$. These findings reformed our perception of stem cells as a functionally uniform pool to that of a dynamic pool of multiple stem cell subsets. They are also resurrecting the question are stem cells distinct and permanent cellular entities or do they exist in several functional sates with distinct phenotypic and functional features ${ }^{28,29}$ ?

The increasingly better characterized heterogeneity among HSCs supports the notion that the HSC pool consists of different cell subsets with distinct phenotypic and functional characteristics ${ }^{5-17}$. In addition, new studies reported further phenotypic and functional heterogeneity among early and lineage-restricted hematopoietic progenitors ${ }^{14,15}$. The range of expression of certain markers (e.g. CD34, CD150, CD229, CD41) on HSCs and differential Hoechst 33342 efflux capacities enabled the identification of functionally distinct HSC subsets, which differ in their self-renewal potential, life-span, cycling status and differentiation potential. More importantly, it appears that some of these HSC subsets are interconvertible and oscillate between functionally distinct states $^{8,10,11,19,22,23}$.

Studies by the Ogawa group were the first to reveal that mouse long-term repopulating HSCs (LTR-HSCs) oscillate in vivo between $\mathrm{CD} 34^{-}$and $\mathrm{CD} 34^{+/ \mathrm{low}}$ states $^{18,19}$. Other studies suggested that mouse LTR-HSCs oscillate between dormant $\mathrm{CD} 34^{-}$and activated $\mathrm{CD} 34^{+}$states $^{22}$. Based on differential expression of CD150 marker and Hoechst dye efflux capacity, several studies have shown that HSCs can be divided into two functionally distinct and potentially interconvertible lineage-biased HSC subsets: (1) a CD150 ${ }^{\text {hi }}$ subset with high propensity to generate myeloid progeny, and (2) a CD150 $0^{\text {low }}$ subset with robust potential for differentiation into lymphoid lineages $s^{6-8,13,14,23}$. 
Consequently, HSCs are now perceived as a complex and dynamic pool of functionally heterogeneous and sometimes interconvertible cell subsets, rather than being a functionally uniform cell population $^{6-8,10,16,23}$. However, the characteristics and regulation of interconvertible HSC subsets remain to be fully explored. Studying HSC interconvertibility in vivo or in vitro is complicated due to difficulties in capturing oscillating cell subsets in vivo and long-term in vitro maintenance of functional $\mathrm{HSCs}^{4}$.

The murine multipotent hematopoietic cell line EML has emerged as a unique model to study heterogeneity and interconvertibility of multipotent hematopoietic cells ${ }^{30-34}$. The EML cell line is SCFdependent and was derived by retroviral expression of truncated, dominant-negative form of human retinoic acid receptor RAR $\alpha 403$ in BM cells from 5-fluorouracil treated BDF1 mice ${ }^{30}$. Importantly, EML cell line has a well-documented multilineage (erythroid, myeloid, lymphoid) differentiation capacity, and is an established in vitro surrogate for multipotent hematopoietic cells $^{30,35-41}$. In the presence of SCF EML cells undergo proliferative self-renewal, while in response to specific cytokines and in presence of specific stromal cells they differentiate into cells of the erythroid, granulocyte-macrophage, megakaryocytic, B cell and T cell lineages (Supplementary Fig. S1) $30,35-41$.

Multiple studies have drawn parallels between EML cells and adult HSCs and multipotent progenitors (MPPs) due to their phenotypic, functional and molecular features. For that reason EML cell line is being increasingly used as an important and biologically relevant model to study the regulation of multipotent hematopoietic cell self-renewal, lineage commitment and differentiation ${ }^{30,35-41}$.

Previous studies have shown that EML cell line is phenotypically and functionally heterogeneous ${ }^{30-32,34,38,39,41}$. Ye et al. reported that EML cell line consists of $\mathrm{Lin}^{-} \mathrm{CD} 34^{+}$replicating cells and $\mathrm{Lin}^{-} \mathrm{CD} 34^{-}$nonreplicating cells which do not grow in the presence of $\mathrm{SCF}^{31}$. Furthermore, that study reported that the $\mathrm{CD} 34^{+}$cell population generates a $\mathrm{CD} 34^{-}$nonreplicating population, and maintains both cell populations within EML cell line $\mathrm{e}^{31}$. The subsequent study by the same group expanded their observations that $\mathrm{Lin}^{-} \mathrm{CD} 34^{+}$cell subset grows rapidly in SCF and can regenerate entire population of EML cells, whereas $\mathrm{Lin}^{-} \mathrm{CD} 34^{-}$subset grows slowly if at all in SCF but can be propagated in the presence of IL- $3^{33}$.

Chang et al. have shown that EML cells exhibit $\sim 1,000$-fold range in the expression level of HSC marker Sca- $1^{32}$. By purification and culture of EML cells with the highest, middle and lowest $~ 15 \%$ Sca-1 expression level (referred to as Sca- $1^{\text {low }}$, Sca- $1^{\text {mid }}$ and Sca- $1^{\text {high }}$ subsets), that study has shown that on a population level each Sca-1 subset is interconvertible and regenerates the parental EML cell population and its phenotypic and functional traits, including the expression pattern of Sca-1 marker, differentiation rates and gene expression profiles. In addition, using methylcellulose cloning Chang et al. generated random single cell-derived clones from total EML cells that expressed varying levels of Sca-1, which over a period of 8 weeks regenerated the original broad expression profile of Sca-1, typical for EML cell line. Based on these findings Chang et al. proposed that interconvertible states of EML cells reflect slowly fluctuating transcriptomes that may govern reversible priming and cell fate decision $^{32}$

A study by Pina et al. characterized interconvertible properties and lineage commitment status of Sca- $1^{\text {lo }}$ EML cells (encompassing the $15 \%$ lowest-staining cells) and Sca- $1^{\text {hi }}$ EML cells (encompassing the $15 \%$ highest-staining cells) $)^{34}$. Although on a population level both Sca- $1^{\text {lo }}$ and Sca- $1^{\text {hi }}$ EML cells have culture-reconstituting capacity, subsequent analysis of the $\mathrm{CD} 34^{+}$and $\mathrm{CD} 34^{-}$fractions of Sca- $1^{\text {lo }}$ EML cells revealed that $\mathrm{Sca}-1^{\text {lo }}$ population consists of erythroid-committed Sca $1^{\text {lo }} \mathrm{CD} 34^{-}$cells with no culture-reconstitution capacity and a culture-reconstituting Sca $1^{\text {lo }} \mathrm{CD} 34^{+}$cells with both erythroid and myeloid differentiation potential. By analyzing the so called culture-reconstituting potential of single Sca- $1^{\text {lo }}, \mathrm{Sca} 1^{\text {lo }} \mathrm{CD} 34^{-}$and
Sca $1^{\text {lo }} \mathrm{CD} 34^{+}$cells over a period of several days, Pina et al. reported that $17 \%$ of Sca- $1^{\text {lo }}, 2.5 \%$ of Sca $1^{\text {lo }} \mathrm{CD} 34^{-}$and $35 \%$ of Sca $1^{\text {lo }} \mathrm{CD} 34^{+}$ cells generated more than 100 cells, which reconstituted broad Sca- 1 expression. These findings led to the conclusion that Sca-1 subsets of EML cells reflect oscillation between self-renewing and committed cell states ${ }^{34}$.

To gain further insight into the heterogeneity and interconvertibility of multipotent hematopoietic cells, in this study we used the broad expression range of the HSC marker CD34 on EML cells to analyze in more depth (1) the phenotypic and functional heterogeneity within EML cell line, and (2) the characteristics and maintenance of interconvertible EML cell subsets.

\section{Results}

EML cell line is phenotypically very heterogeneous and consists of multiple cell subsets with distinct expression pattern of HSC markers. To gain further insight into heterogeneity within EML cell line we examined the expression of a panel of HSC cell surface markers ${ }^{5,42-49}$. Flow cytometry analysis has shown that all or nearly all EML cells are Sca- $1^{+}$c-kit ${ }^{+}$Flk2 ${ }^{-}$and alpha2-integrin $(\mathrm{CD} 49 \mathrm{~b})^{-}$, but exhibit heterogeneous expression of CD34, CD27, VEGFR1, CD201 and CD150 (Fig. 1a,b and Supplementary Fig. S2).

Division of HSCs into $\mathrm{CD} 150^{\text {neg }}, \mathrm{CD} 150^{\text {low }}, \mathrm{CD} 150^{\text {int }}$ and CD150 high subsets based on the range of CD150 marker expression has revealed that these subsets display distinct in vivo functional features and differential lineage transcriptional priming ${ }^{6,15}$. Furthermore, expression range of CD34 marker is used to distinguish LTRHSCs from short-term repopulating HSCs (STR-HSCs), and perhaps dormant from activated LTR-HSCs ${ }^{22,42,44}$. Similarly, fractionation of EML cells into Sca- $1^{\text {low }}, \mathrm{Sca}-1^{\text {mid }}$ and Sca- $1^{\text {high }}$ subsets based on the broad expression range of Sca-1 marker has enabled characterization of EML Sca-1 cell subsets ${ }^{31,32,34}$.

EML cells also exhibit a broad expression range of CD34, similar to that of Sca-1 (Fig. 1a,c) ${ }^{32}$. Using equal increments of fluorescence intensity we divided EML cells into CD $34^{\text {neg }}, \mathrm{CD} 34^{\text {low }}, \mathrm{CD} 34^{\text {int }}$ and CD34 ${ }^{\text {high }}$ cell subsets (referred to in further text as EML CD34 cell subsets), designating the cells that do not express CD34, and cells expressing low, intermediate and high levels of CD34 (Fig. 1c). This approach enabled us to reproducibly and consistently purify these EML cell subsets, and study their heterogeneity and interconvertibility.

Although the frequency of each EML CD34 cell subset fluctuates slightly, their average frequency remains quite stable throughout multiple cell passages. Further analysis of EML CD34 cell subsets revealed phenotypic heterogeneity and distinct expression profiles of CD27, CD201, VEGFR1 and CD150 markers within each cell subset. For example, CD34 $4^{\text {neg }}$ and $\mathrm{CD} 34^{\text {low }}$ subsets contain the highest percentage of $\mathrm{VEGFR}^{+}$cells and the lowest percentage of $\mathrm{CD} 150^{+}$ and $\mathrm{CD} 27^{+}$cells, whereas $\mathrm{CD} 34^{\text {int }}$ and $\mathrm{CD} 34^{\text {high }}$ subsets contain the highest percentage of $\mathrm{CD} 150^{+}$and $\mathrm{CD} 201^{+}$cells (Fig. $1 \mathrm{~d}$ and Supplementary Fig. S3).

Flow cytometry analysis of co-expression of CD34 and Sca-1 markers revealed further differences between EML CD34 subsets. The CD3 $4^{\text {neg }}$ subset reproducibly exhibits the broadest range of Sca-1 expression, which gradually narrows from $\mathrm{CD} 34^{\text {low }}$ to $\mathrm{CD} 34^{\text {int }}$ and CD34 $4^{\text {high }}$ cell subsets (Supplementary Fig. S4). Although the majority of cells in the CD34 $4^{\text {neg }}$ subset are Sca- $1^{+}$, this is the only subset that also contains Sca- $1^{\text {neg }}$ cells. In contrast, the cells in CD34 ${ }^{\text {high }}$ subset express the highest levels of Sca-1 (Supplementary Fig. S4).

EML CD34 cell subsets are functionally diverse and display distinct multilineage differentiation patterns, cell cycle profiles and proliferation kinetics. To investigate the functional characteristics of EML CD34 cell subsets, we analyzed their multilineage differentiation potential, cell cycle profile and proliferation kinetics. Multilineage differentiation of FACS purified $\mathrm{CD} 34^{\text {neg }}, \mathrm{CD} 34^{\text {low }}$, 
a

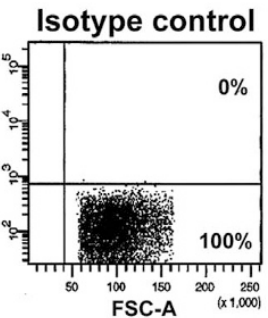

CD34

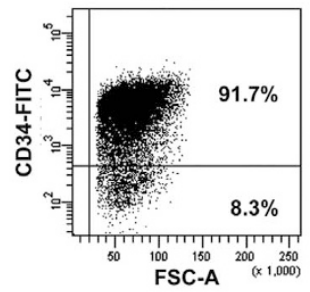

c-kit

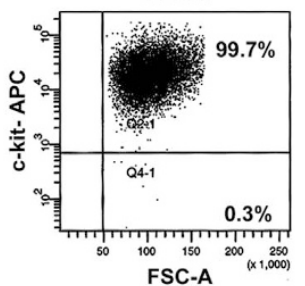

CD150

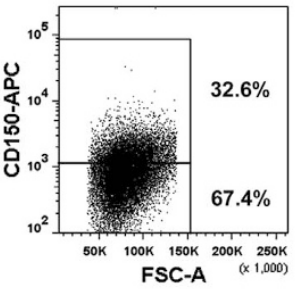

Sca-1

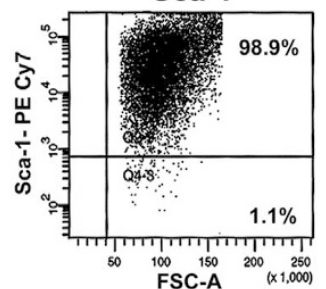

CD201

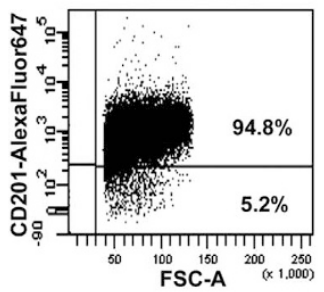

Flk-2

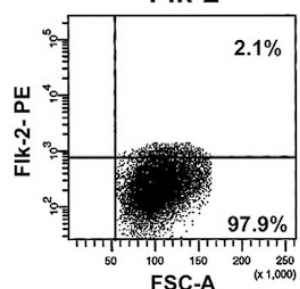

VEGFR1

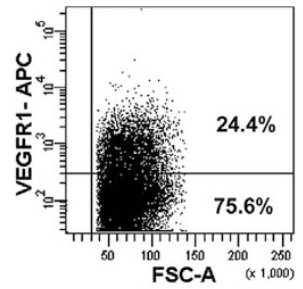

CD49b

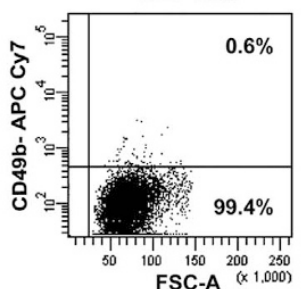

CD27

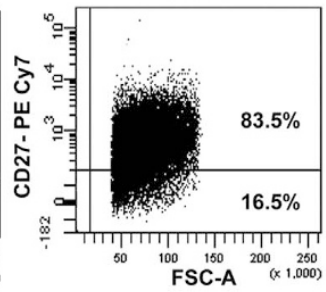

b

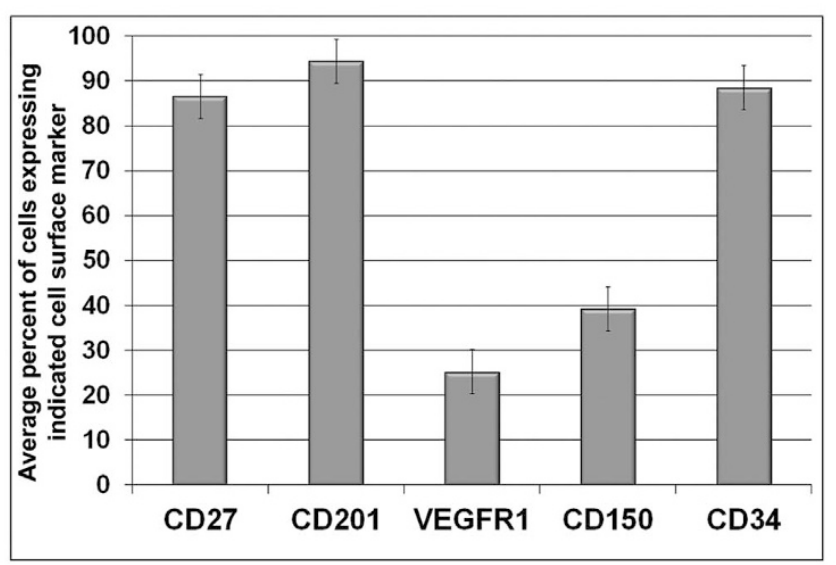

C

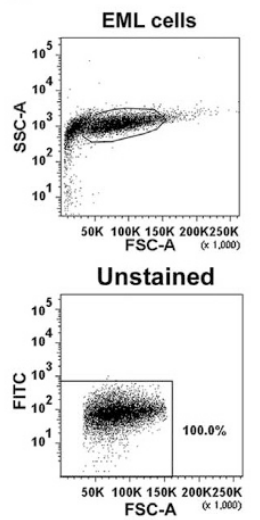

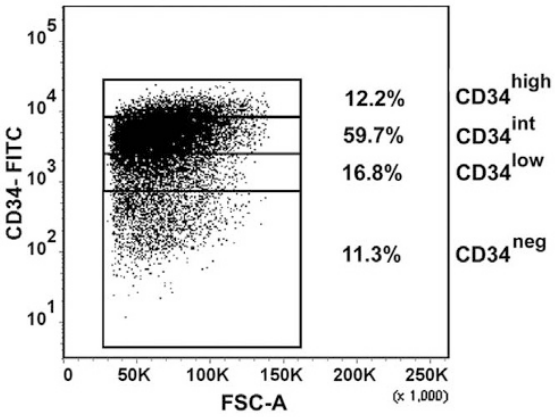

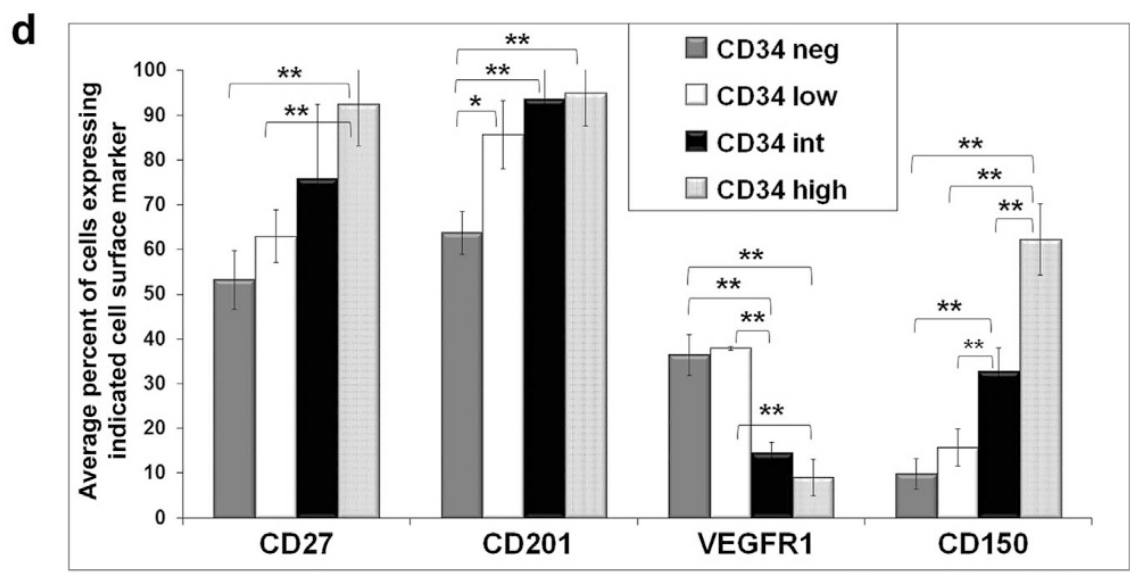

Figure 1 The multipotent hematopoietic cell line EML is phenotypically heterogeneous and consists of several cell subsets with distinct expression patterns of HSC markers. (a) Representative flow cytometry analysis of the expression of a panel of HSC markers on EML cells showing that almost all EML cells are Sca- $1^{+}$c-kit ${ }^{+}$Flk2 ${ }^{-}$and alpha2-integrin (CD49b) ${ }^{-}$, but exhibit heterogeneous expression of CD34, CD27, VEGFR1, CD201 and CD150 $(n=6)$. (b) Average percent of EML cells expressing CD27, CD201, VEGFR1, CD150 and CD34 markers $(n=6)$. Data are mean \pm SD. (c) Representative flow cytometry analysis showing division of EML cells into CD34 $4^{\text {neg }}, \mathrm{CD} 34^{\text {low }}, \mathrm{CD} 34^{\text {int }}$ and $\mathrm{CD} 34^{\text {high }}$ cell subsets based on the broad range of expression of the CD34 marker $(n=15)$. (d) Histograms show the results of flow cytometry analysis of CD27, CD201, VEGFR1 and CD150 expression on $\mathrm{CD} 34^{\text {neg }}, \mathrm{CD} 34^{\text {low }}, \mathrm{CD} 34^{\text {int }}$ and CD34 ${ }^{\text {high }}$ EML cell subsets $(n=3-9)$. Data are mean $\pm \mathrm{SD}$. $* P$ value $<0.05, * * P$ value $<0.001$.

$\mathrm{CD} 34^{\text {int }}$ and $\mathrm{CD} 34^{\text {high }}$ cell subsets ( $\sim 99 \%$ purity, $\geq 95 \%$ viability) was assessed by colony-forming cell (CFC) assays for hematopoietic progenitors $^{37,38}$. CFC assays revealed that only a very small percentage of $\mathrm{CD} 34^{\text {neg }}$ cells forms erythroid (BFU-E) and granulocyte- macrophage (CFU-GM) colonies (Fig. 2a). The CD34 ${ }^{\text {neg }}$ cells that do not form colonies are visible as viable single cells for up to 5 days after plating. During that period these cells do not divide at all, and around day 5 they begin to die and are visible as cell debris. This 
a

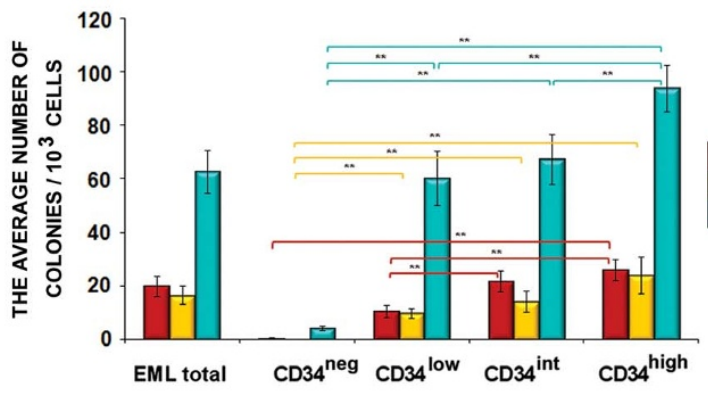

\begin{tabular}{|c|c|c|c|}
\hline $\begin{array}{c}\text { \# of colonies/ } \\
10^{3} \text { cells }\end{array}$ & $\begin{array}{c}\text { BFU-E } \\
\text { Mean } \pm \mathrm{SD}\end{array}$ & $\begin{array}{c}\text { CFU-Meg } \\
\text { Mean } \pm \mathrm{SD}\end{array}$ & $\begin{array}{c}\text { CFU-GM } \\
\text { Mean } \pm \mathrm{SD}\end{array}$ \\
\hline EML total & $19.8 \pm 3.76$ & $16.4 \pm 3.43$ & $62.6 \pm 8.1$ \\
\hline CD34 & $0.4 \pm 0.2$ & 0 & $4.2 \pm 0.84$ \\
\hline CD34 & $10.4 \pm 2.3$ & $9.8 \pm 1.79$ & $60.2 \pm 10.18$ \\
\hline CD34 $^{\text {low }}$ & $21.6 \pm 4.03$ & $14.2 \pm 3.96$ & $67.25 \pm 9.36$ \\
\hline CD34 $^{\text {high }}$ & $25.8 \pm 3.89$ & $23.8 \pm 6.83$ & $93.6 \pm 8.65$ \\
\hline
\end{tabular}

b

Cell cycle analysis
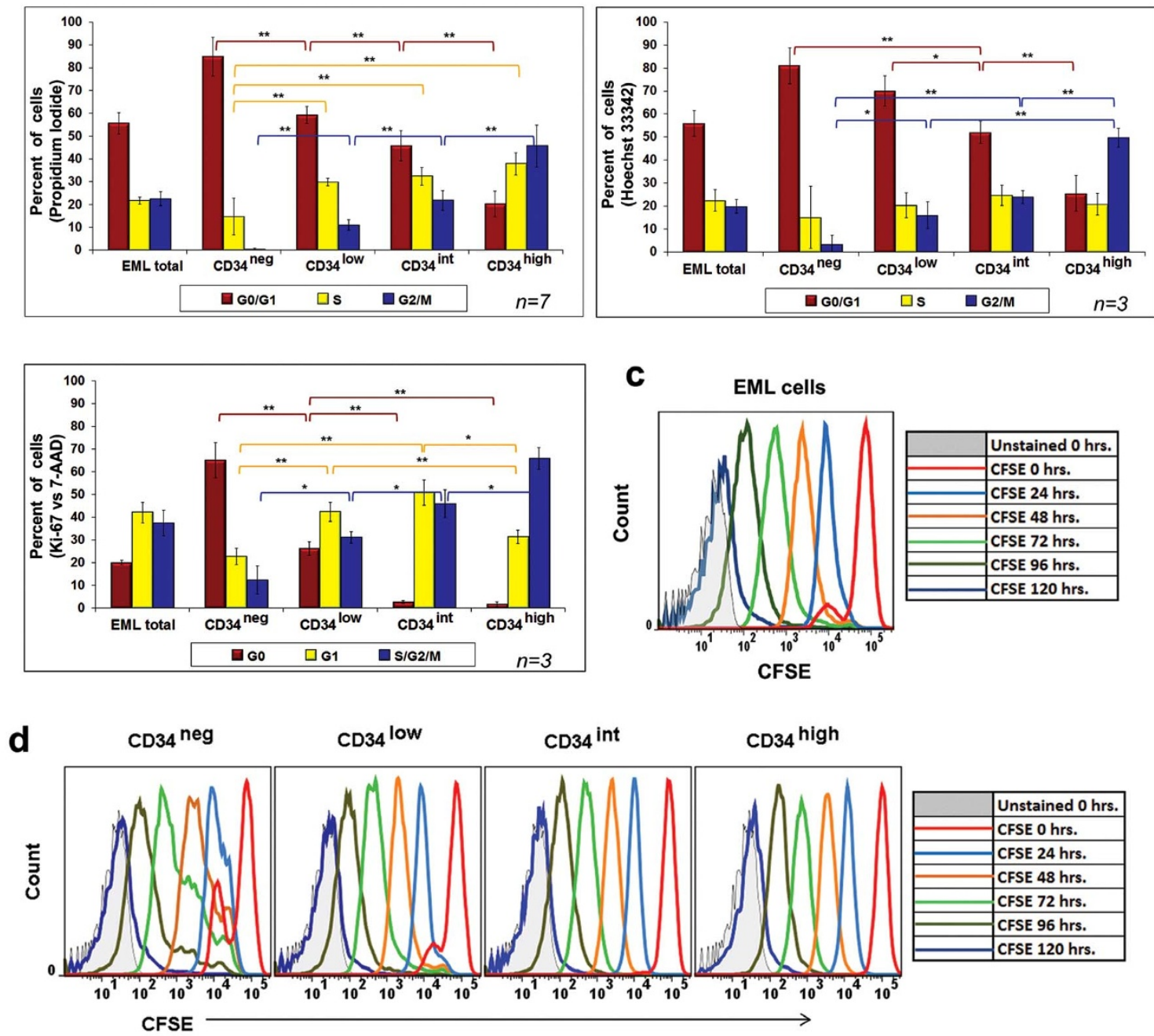

Figure $2 \mid$ EML CD34 cell subsets exhibit distinct multilineage differentiation patterns, cell cycle profiles and proliferation kinetics. (a) Colonyforming cell (CFC) assay analysis of the differentiation capacity of total EML cells and purified CD $34^{\text {neg }}, \mathrm{CD} 34^{\text {low }}, \mathrm{CD} 34^{\text {int }}$ and CD34 $4^{\text {high }} \mathrm{EML}$ cell subsets into erythroid, megakaryocytic and granulocyte-macrophage lineages $(n=15)$. The histograms and the table show the numbers of granulocytemacrophage (CFU-GM), megakaryocytic (CFU-Meg) and erythroid (BFU-E) colonies generated by total EML cells and each EML CD34 cell subset $\left(10^{3}\right.$ cells/well) in the presence of cytokines IL-3, Tpo and Epo, respectively. Data are mean \pm SD. $*$ P value $<0.05$, ** P value $<0.001$. (b) Analysis of cell cycle profiles of total EML cells and CD34 $4^{\text {neg }}, C D 34^{\text {low }}, C D 34^{\text {int }}$ and CD $34^{\text {high }}$ EML cell subsets using Propidium Iodide, Hoechst 33342 and Ki-67 vs 7-AAD staining $(n=3-5)$. Data are shown as mean $\pm \mathrm{SD} .{ }^{*} P$ value $<0.05, * * P$ value $<0.001$. (c) Flow cytometry analysis of proliferation kinetics of total EML cells by CFSE labeling. The grey-shaded histogram on the left side of the panel shows unlabeled cell auto-fluorescence and the limits of detectable cell divisions. The histogram outlined in red on the right side of the panel shows CFSE signal in EML cells immediately after the labeling. The overlay of CFSE signal at 24 hour time points following labeling shows EML cell division history. During each cell division CFSE is partitioned equally among daughter cells, resulting in a corresponding uniform decrease in CFSE fluorescence among all dividing cells. Synchronous cell divisions result in a corresponding uniform decrease in CFSE signal among all dividing cells and narrow fluorescence histograms. $(n=2)$. (d) Analysis of proliferation kinetics of CD34 ${ }^{\text {neg }}$, $\mathrm{CD} 34^{\text {low }}, \mathrm{CD} 34^{\text {int }}$ and CD34 ${ }^{\text {high }}$ EML cell subsets by CFSE labeling. The overlay of CFSE signal at 24 hour time points following labeling shows division history and proliferation kinetics of each EML cell subset. The cells within CD34 ${ }^{\text {neg }}$ subset exhibited more asynchronous and slower division at each time point (see also Supplementary Fig. S5), as shown by varying levels or CFSE fluorescence resulting in broader and overlapping histograms at different time points after CFSE labeling $(n=4)$. 
observation indicates that cytokines IL-3, Epo or Tpo do not induce differentiation or support survival of the majority of cells within the $\mathrm{CD} 34^{\text {neg }}$ subset. In contrast, the percentage of cells forming granulocyte-macrophage, erythroid and megakaryocytic (CFUMeg) colonies increases from CD34 ${ }^{\text {low }}$ to CD $34^{\text {high }}$ cells (Fig. 2a), indicating an increased content of colony-forming progenitors in these EML cell subsets. Notably, these findings are very similar to a report that mouse $\mathrm{Lin}^{-} \mathrm{Sca}-1^{+}{\mathrm{c}-\mathrm{kit}^{+}}^{+}$(LSK) CD34 ${ }^{\text {high }} \mathrm{BM}$ cells differentiate efficiently into myelo-erythroid lineages, whereas $\mathrm{CD} 34^{\text {low }}$ and $\mathrm{CD}^{-} 4^{-} \mathrm{BM}$ cells differentiate minimally or not at all $^{19}$.

Analyses of the cell cycle profiles by PI, Hoechst 33342, and Ki-67/ 7-AAD staining (Fig. 2b) have all shown that each EML CD34 cell subset contains a significantly different percentage of cells in G0/G1 and S/G2/M phases when compared to other subsets. While a large proportion of $\mathrm{CD} 34^{\text {neg }}$ cells are in G0/G1 phase, the percentage of cells in $\mathrm{S}$ and $\mathrm{G} 2 / \mathrm{M}$ gradually, but significantly, increases from CD34 ${ }^{\text {low }}$ to $\mathrm{CD} 34^{\text {high }}$ cell subset (Fig. 2b).

To examine their proliferation kinetics, total EML cells and purified EML CD34 cell subsets were labeled with CFSE and their division evaluated at 24 hour time points for 5 days (Fig. 2c,d). The CFSE assay revealed that total EML cells divide quite synchronously, with only a small proportion of cells dividing more slowly (Fig. $2 \mathrm{c}$ and Supplementary Fig. S5). Remarkably, CFSE labeling uncovered the existence of two distinct cell populations within total EML cells: a prominent large CFSE $^{\text {Main }}$ population with uniformly high level of CFSE signal, and a much smaller CFSE ${ }^{\text {Satellite }}$ population with lower level of CFSE signal immediately after labeling (Supplementary Fig. $\mathrm{S} 5 \mathrm{~b})$. The CFSE ${ }^{\text {Main }}$ population is very similar to total EML cells in terms of their CD34 expression pattern and the relative frequency of $\mathrm{CD} 34^{\text {neg }}, \mathrm{CD} 34^{\text {low }}, \mathrm{CD} 34^{\text {int }}$ and CD34 $4^{\text {high }}$ cell subsets. In contrast, the CFSE $^{\text {Satellite }}$ population of EML cells consists mainly of CD $34^{\text {neg }}$ and CD $34^{\text {low }}$ cells (Supplementary Fig. S5b,c).

The cells within the $\mathrm{CD} 34^{\text {high }}$ and $\mathrm{CD} 34^{\text {int }}$ subsets also divide quite synchronously, whereas a small fraction of cells in CD34 ${ }^{\text {low }}$ subset divides asynchronously (Fig. 2d and Supplementary Fig. S6a). In contrast, the cells within the $\mathrm{CD} 34^{\text {neg }}$ subset divide more asynchronously, with a portion of cells dividing slower than the rest (Fig. 2d and Supplementary Fig. S6a).

CFSE labeling of EML CD34 subsets also uncovered the existence of distinct $\mathrm{CFSE}^{\text {Main }}$ and CFSE ${ }^{\text {Satellite }}$ subpopulations mainly within the CD $34^{\text {neg }}$ and CD34 ${ }^{\text {low }}$ cell subsets (Supplementary Fig. S6b). The frequency of $\mathrm{CFSE}^{\text {Satellite }}$ cells is the highest in the CD34 ${ }^{\text {neg }}$ subset $(22.68 \pm 6.7 \%)$, while the $\mathrm{CD} 34^{\text {low }}$ cell subset contains lower frequency $(9.4 \pm 5.01 \%)$ of CFSE ${ }^{\text {Satellite }}$ cells. On the other hand, the CD34 $4^{\text {int }}$ and CD34 $4^{\text {high }}$ cell subsets contain a very small percentage of CFSE $^{\text {Satellite }}$ cells $(1.03 \pm 0.56 \%$ and $0.45 \pm 0.37 \%$, respectively) (Supplementary Fig. S6b). Temporal tracking of the CFSE signal in the progeny of each EML CD34 cell subset in relation to CFSE ${ }^{\text {Main }}$ and CFSE $^{\text {Satellite }}$ populations further illustrates asynchronous and slower proliferation of cells in the CD $34^{\text {neg }}$ and CD $34^{\text {low }}$ subsets in comparison to CD34 ${ }^{\text {int }}$ and CD34 ${ }^{\text {high }}$ cell subsets (Supplementary Fig. S6c).

Overall, CFSE assays revealed additional heterogeneity within EML cell line, and additional differences between the CD34 $4^{\text {neg }} /$ CD $34^{\text {low }}$ and $\mathrm{CD} 34^{\text {int }} / \mathrm{CD} 34^{\text {high }}$ cell subsets, which may be due to (1) increased CFSE efflux capacity of CFSE ${ }^{\text {Satellite }}$ cells, or (2) reduced activity or amount of intracellular esterases required to remove acetate groups and render CFSE fluorescent.

Cumulatively, these studies revealed additional phenotypic and functional diversity within EML cell line, and support the notion that in terms of their phenotypic and functional features the $\mathrm{CD} 34^{\text {neg }}$ and CD34 ${ }^{\text {low }}$ subsets are most similar to each other and share many phenotypic and functional features, whereas on the other end the CD $34^{\text {int }}$ and $\mathrm{CD} 34^{\text {high }}$ subsets share most similarities.

Hematopoietic transcriptional signatures of EML CD34 cell subsets. To start identifying molecular differences between EML CD34 cell subsets we analyzed transcriptomes in (1) three independent samples of total EML cells, and (2) three independently purified samples of $\mathrm{CD} 34^{\text {neg }}$ cells and combined CD34 ${ }^{\text {int }}$ and CD34 $4^{\text {high }}$ subsets, referred to in text as $\mathrm{CD} 34^{+}$cells. To compare hematopoietic transcriptional signatures of these EML cell subsets we specifically examined expression of (1) genes important for overall hematopoiesis and HSC maintenance and function, (2) hematopoietic cell surface markers, receptors and adhesion molecules, and (3) genes associated with erythroid, megakaryocytic, myeloid and lymphoid lineage development and specification ${ }^{50-52}$ (Supplementary Tables $1,2,3)$.

Analysis of microarray data detected little or no difference in expression ( $\leq 1.5$-fold change) of the majority of genes examined in CD34 $4^{\text {neg }}$ and CD34 ${ }^{+}$EML cells (Supplementary Tables 1,2,3). Genes whose expression was higher in CD $34^{\text {neg }}$ EML cells included: GATA-1, junctional adhesion molecule 4 (JAM4), CD38 (another mouse HSC marker), Tie2/TEK, HSC-derived tyrosine kinase STK (RON), a receptor for Macrophage-stimulating protein (MSP), Evi1, Hes1, Klf1 (Kruppel-like factor 1 erythroid) and VWF (Supplementary Tables 1,2,3). Genes found to be down-regulated in $\mathrm{CD} 34^{\text {neg }}$ EML cells included: PU.1, C/EBP $\alpha, C D 34, C D 27$ (Fig. 1c, d), JAM3, Id1, Tnfrsf1 $\alpha$, Lck, TdT and Tcf7 (Supplementary Tables 1,2,3). The expression of transcript for Tcf7 gene (a transcriptional activator that plays an important role in lymphocyte differentiation) was recently found to be significantly downregulated in $\mathrm{Sca}_{-} 1^{-} \mathrm{CD} 34^{-}$EML cells in comparison to $\mathrm{Sca}-1^{+}$ CD34 ${ }^{+}$cells $^{38}$.

Of particular interest among the genes differentially expressed between $\mathrm{CD} 34^{\text {neg }}$ and CD34 ${ }^{+}$EML cells are transcription factors GATA-1, PU.1 and C/EBP $\alpha^{53-57}$ (Fig. 3). PU.1 and GATA-1 play key roles in myeloid and erythroid lineage specification and restriction $^{53,54}$. Their reciprocal repression controls the erythroid versus myeloid fate decisions ${ }^{53,54}$. C/EBP $\alpha$ controls developmental fate of multipotent progenitors and HSCs by actively promoting myeloid differentiation and inhibiting erythroid differentiation ${ }^{55,56}$. The latest study reported that $\mathrm{C} / \mathrm{EBP} \alpha$ is required for myeloid lineage priming of HSCs, and that deletion of $\mathrm{C} / \mathrm{EBP} \alpha$ results in loss of self-renewal and HSC exhaustion ${ }^{57}$.

Previous studies reported that Sca- $1^{\text {low }}$ and Sca- $1^{\text {low }} \mathrm{CD} 34^{-}$EML cells express significantly higher levels of GATA-1 transcript and protein than Sca- $1^{\text {med }}, \mathrm{Sca}-1^{\text {high }}$, and Sca $1^{\text {low }} \mathrm{CD} 34^{+} \mathrm{EML} \mathrm{cells}^{32,34}$. Chang et al. have also observed that Sca- $1^{\text {high }}$ and Sca- $1^{\text {med }}$ EML cells express significantly higher levels of PU.1 transcript and protein than Sca- ${ }^{\text {low }}$ EML cells ${ }^{32}$. Earlier microarray studies also revealed much higher expression of $\mathrm{C} / \mathrm{EBP} \alpha$ transcript in $\mathrm{Sca}^{+} \mathrm{CD} 34^{+} \mathrm{EML}$ cells in contrast to $\mathrm{Sca}^{-} \mathrm{CD} 34^{-} \mathrm{EML}^{-}$cells ${ }^{41}$.

Our microarray data indicated that the expression of GATA-1 is higher in CD $34^{\text {neg }}$ EML cells and the expression of PU.1 and C/EBP $\alpha$ is higher in $\mathrm{CD}_{3} 4^{+}$cells (Supplementary Tables 1,2,3). Thus, we first analyzed the expression of GATA-1, PU.1, C/EBP $\alpha$ genes in purified $\mathrm{CD} 34^{\text {neg }}, \mathrm{CD} 34^{\text {low }}, \mathrm{CD} 34^{\text {int }}$ and $\mathrm{CD} 34^{\text {high }}$ EML cell subsets by quantitative real-time RT-PCR (qRT-PCR) (Fig. 3a).

qRT-PCR analysis revealed significant differences in the expression of GATA-1 and PU.1 transcripts among EML CD34 subsets with (1) the expression of GATA-1 being significantly higher in the CD $34^{\text {neg }}$ and CD $34^{\text {low }}$ cells than in the CD $34^{\text {int }}$ and CD $34^{\text {high }}$ cells, and (2) the expression of PU.1 being the highest in the CD $34^{\text {high }}$ cells and significantly lower in the CD34 $4^{\text {int }}, \mathrm{CD} 34^{\text {low }}$ and CD $34^{\text {neg }}$ subsets (Fig. 3a). qRT-PCR has also shown that CD34 ${ }^{\text {high }}$ and CD34 $4^{\text {int }}$ cells express similar but significantly higher levels of $\mathrm{C} / \mathrm{EBP} \alpha$ transcript than CD34 ${ }^{\text {neg }}$ and CD34 ${ }^{\text {low }}$ cells (Fig. 3a).

The microarray data also indicated that $\mathrm{CD} 34^{\text {neg }}$ EML cells express higher level of junctional adhesion molecule 4 (JAM4), which is transcribed in LSK CD34- and LSK CD34 ${ }^{+}$BM cells containing HSCs and MPPs, but not in more differentiated BM cells ${ }^{58}$ (Supplementary Tables 1,2,3). qRT-PCR has shown that the express- 
a

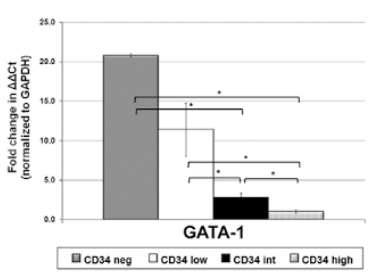

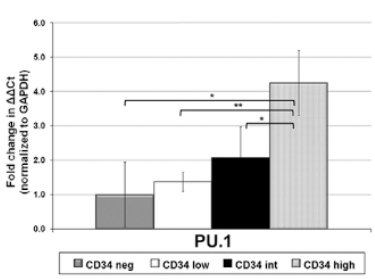
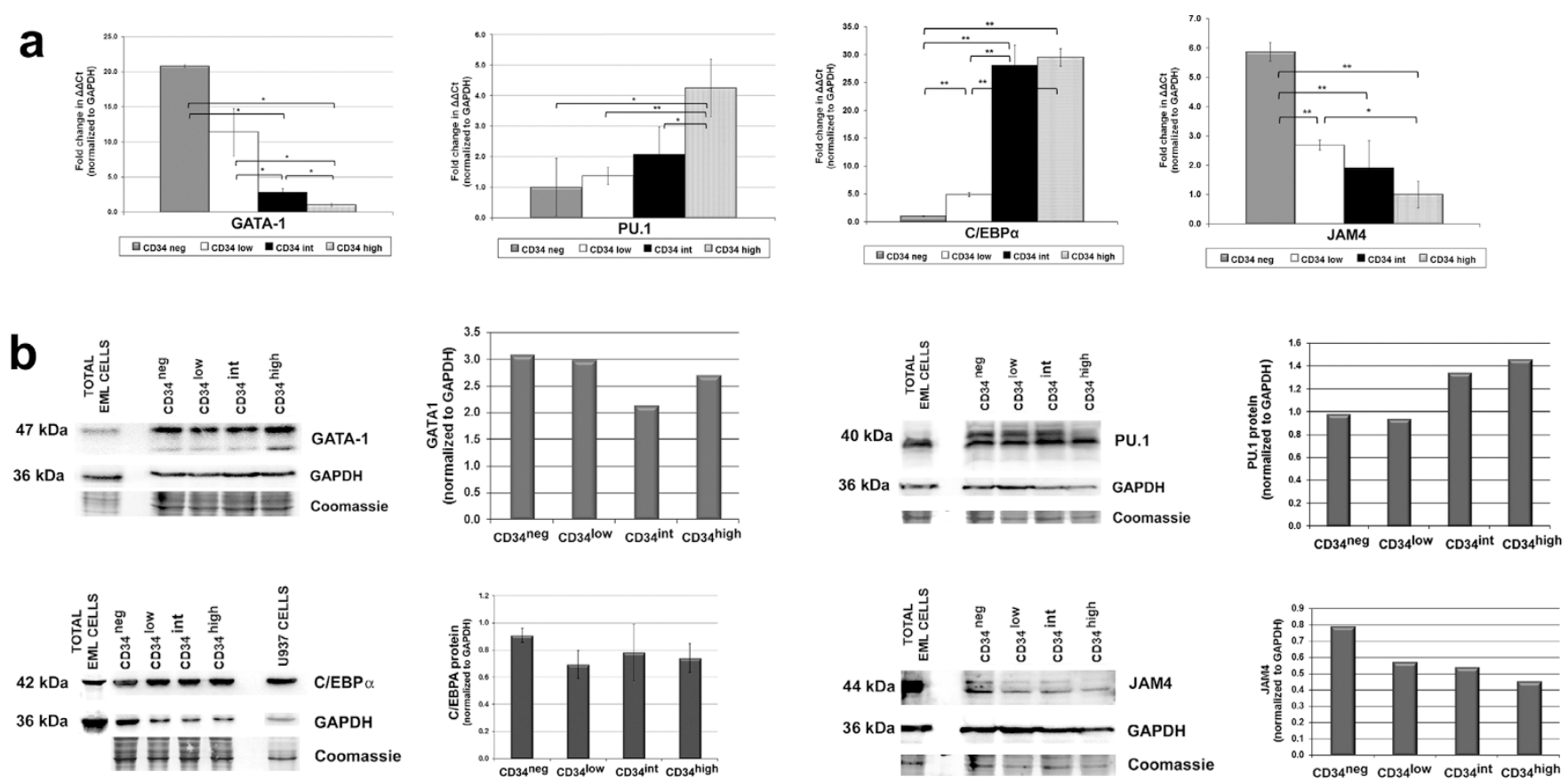

Figure 3 Analysis of hematopoietic transcriptional signatures in EML CD34 cell subsets. To identify molecular differences between EML CD34 cell subsets the transcriptomes of purified CD $34^{\text {neg }}$ cells and combined CD $34^{\text {int }}$ and CD $34^{\text {high }}$ subsets, refrerred to in the text as CD $34^{+}$cells, were analyzed using Agilent microarrays. This analysis focused specifically on expression of (1) genes important for overall hematopoiesis and HSC maintenance and function, (2) hematopoietic cell surface markers, receptors and adhesion molecules, and (3) genes associated with erythroid, megakaryocytic, myeloid and lymphoid lineage specification and development. (a) The quantitative real-time RT-PCR expression analysis of transcription factors GATA1, PU.1 and C/EBP $\alpha$, and adhesion molecule JAM4 in purified CD34 $4^{\text {neg }}, \mathrm{CD} 34^{\text {low }}, \mathrm{CD} 34^{\text {int }}$ and CD $34^{\text {high }}$ EML cells $(n=3)$. Data are shown as mean + SD. * $\mathrm{P}$ value $<0.05,{ }^{* *} \mathrm{P}$ value $<0.01$. (b) Representative Western analysis of GATA-1, PU.1, C/EBP $\alpha$ and JAM4 protein expression in total EML cells and purified CD34 $4^{\text {neg }}, \mathrm{CD} 34^{\text {low }}, \mathrm{CD} 34^{\text {int }}$ and CD34 ${ }^{\text {high }}$ EML cell subsets. Cell lysates from U-937 cells were used as positive controls $(n=3)$. The histograms show the levels of GATA-1, PU.1, C/EBP $\alpha$ and JAM4 proteins in each EML CD34 cell subset normalized to GAPDH protein levels. The levels of GATA-1, PU.1, C/EBP $\alpha$, JAM4 and GAPDH proteins in each sample were measured by densitometric scanning and analyzed with ImageJ software. The staining of gels with Coomassie Brilliant Blue shows loading of proteins from total EML cells and EML CD34 cell subsets.

ion of JAM4 transcript is indeed significantly higher in CD34 ${ }^{\text {neg }}$ cells than in $\mathrm{CD} 34^{\text {low }}, \mathrm{CD} 34^{\text {int }}$ and $\mathrm{CD} 34^{\text {high }}$ cells, thus confirming microarray data (Fig. 3a).

The expression of GATA-1, PU.1, C/EBP $\alpha$ and JAM4 in purified EML CD34 cell subsets was further examined by Western analysis. The expression of GATA-1 protein was found to be higher in the $\mathrm{CD} 34^{\text {neg }}$ and $\mathrm{CD} 34^{\text {low }}$ cells than in the CD $34^{\text {int }}$ and CD $34^{\text {high }}$ cells, while the expression of PU.1 protein was found to be higher in the $\mathrm{CD} 34^{\text {high }}$ and $\mathrm{CD} 34^{\text {int }}$ cells than in the $\mathrm{CD} 34^{\text {low }}$ and $\mathrm{CD} 34^{\text {neg }}$ cells (Fig. 3b).

Notably, although the $\mathrm{CD} 34^{\text {high }}$ and $\mathrm{CD} 34^{\text {int }}$ cells express much higher levels of $\mathrm{C} / \mathrm{EBP} \alpha$ transcript than $\mathrm{CD} 34^{\text {neg }}$ and $\mathrm{CD} 34^{\text {low }}$ cells, Western analysis detected no significant difference in the expression of $\mathrm{C} / \mathrm{EBP} \alpha$ protein among EML CD34 cell subsets (Fig. 3a,b).

On the other hand, the expression pattern of JAM4 protein in purified EML CD34 cell subsets was very similar to expression pattern of JAM4 transcript, with the expression of JAM4 protein being the highest in the CD34 ${ }^{\text {neg }}$ cells and the lowest in the CD34 $4^{\text {high }}$ cells (Fig. 3a,b).

EML cell line consists of interconvertible cell subsets which are maintained and coexist in a dynamic but stable equilibrium. Using phenotypic and functional signatures of EML cell subsets as a blueprint, we interrogated the developmental relationships and maintenance of all EML CD34 cell subsets during multiple passages and cell generations. Multiple batches of each EML CD34 cell subset were purified and subsequently cultured independently (Fig. 4a). To minimize the cross-contamination between cell subsets and variable cell viability, only the cells from sorts yielding the highest cell purity ( $>99 \%)$ and viability ( $>95 \%)$ were used in these experiments. Multiple independent cultures of purified EML CD34 cell subsets were maintained by serial cell passage for up to 14 days, and expression of CD34 on the progeny of each subset analyzed every 2 days (Fig. $4 a)$.

The temporal analysis of the primary progeny of each EML cell subset has shown that already by day 12 of culture each EML CD34 cell subset gave rise to all other cell subsets and re-established the broad expression pattern of CD34 marker typical for parental EML cell population (Fig. 4a and Supplementary Fig. S7). These results are quite similar to previously reported regeneration of the parental EML cell population and its broad range of Scal marker expression by purified Sca-1 cell subsets ${ }^{31}$. However, the temporal kinetics with which each EML CD34 cell subset generated other subsets and reestablished the parental EML cell population differed, with CD34 ${ }^{\text {neg }}$ cells exhibiting the slowest and CD34 ${ }^{\text {high }}$ cells showing the fastest kinetics (Fig. 4a and Supplementary Fig. S7).

In another set of experiments we analyzed expression of HSC markers on and cell cycle profiles of total day 14 progeny of independently cultured parental EML cells and purified CD34 cell subsets. The expression patterns of CD27, VEGFR1, CD201 and CD150 markers on total progeny of parental EML cells and each CD34 cell subset were very similar to and not significantly different from the pattern on parental EML cells (Fig. $4 \mathrm{~b}$ and $1 \mathrm{~b}$ ). Moreover, all new CD34 cell subsets, generated either by parental EML cells or by each parental CD34 cell subset, exhibited the heterogeneous expression patterns of CD27, VEGFR1, CD201 and CD150 markers, typical of the parental EML CD34 cell subsets (Fig. 5a,b and Fig. 1d). For example, both among parental EML cell subsets and their progeny, 

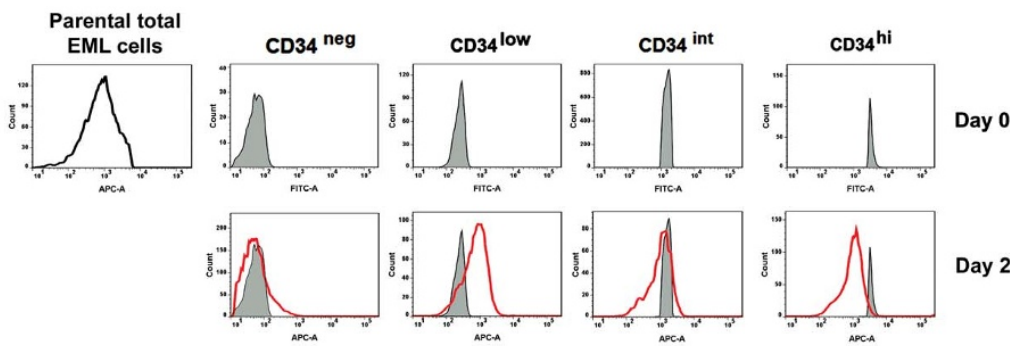

Day 2
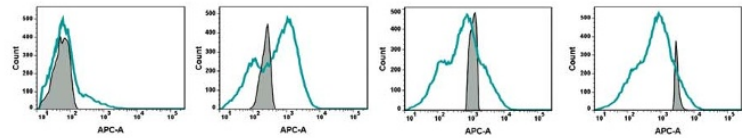

Day 4
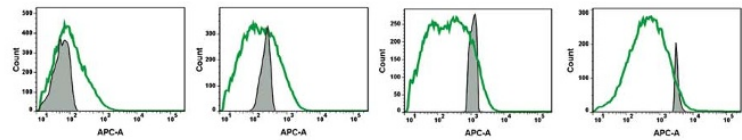

Day 6
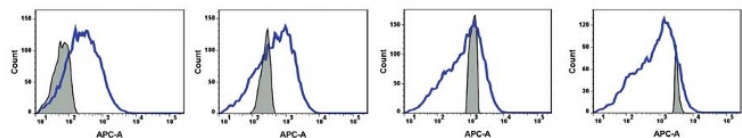

Day 8
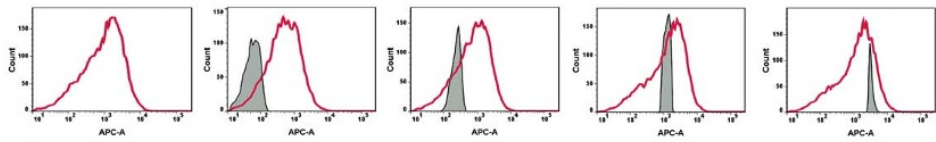

Day 14

b

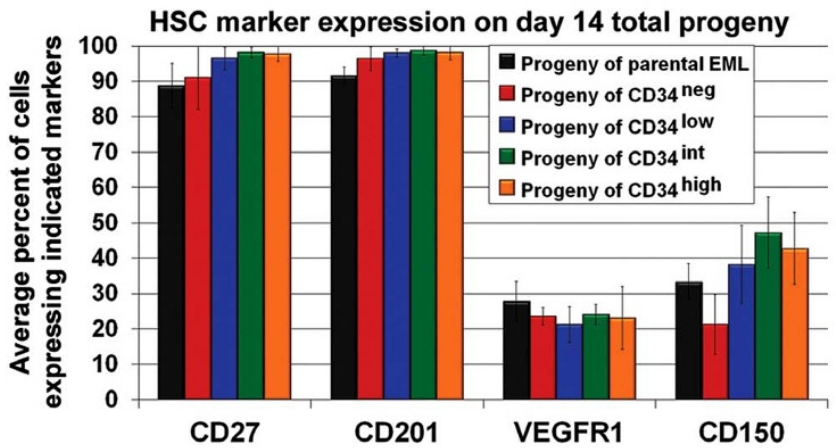

C

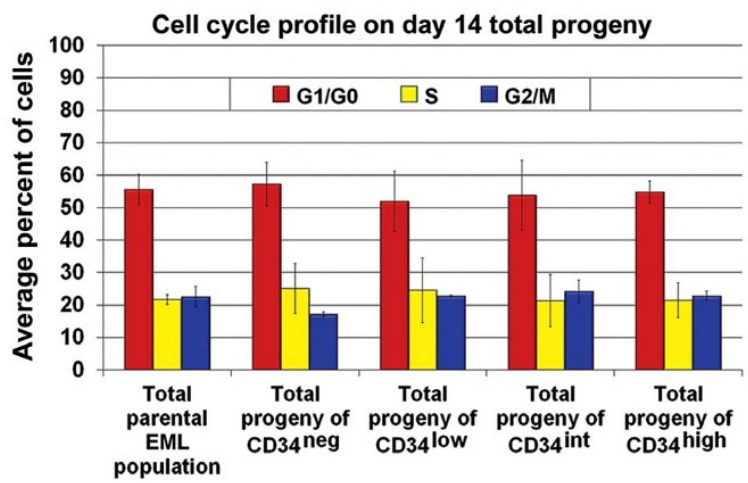

Figure $4 \mid$ Temporal analyses of the progeny of each EML CD34 cell subset showing that each EML cell subset has the capacity to generate all other CD34 cell subsets and re-establish the entire parental EML cell population. (a) Multiple batches of CD34 $4^{\text {neg }}$, CD3 $4^{\text {low }}$, CD3 $4^{\text {int }}$ and CD34 ${ }^{\text {high }}$ EML cell subsets were purified by FACS. To minimize the cross-contamination between cell subsets and variable cell viability, only the cells from sorts yielding the highest cell purity $(>99 \%)$ and viability $(>95 \%)$ were used in these experiments. Independent cultures of each purified CD34 cell subset were maintained by serial cell passage for 14 days. Representative flow cytometry density plots showing temporal changes of the CD34 expression on the progeny of each EML CD34 cell subset over 14 days of culture, and re-establishment of the broad expression range of CD34 marker typical for parental EML cell population $(n=3)$. (b) The parental EML cells and purified CD $34^{\text {neg }}, \mathrm{CD} 34^{\text {low }}, \mathrm{CD} 34^{\text {int }}$ and CD $34^{\text {high }}$ cell subsets were cultured independently for 14 days, and the expression of CD27, VEGFR1, CD201 and CD150 markers on their total day 14 progeny analyzed by flow cytometry $(n=2)$. Data are mean \pm SD. (c) The cell cycle profiles of day 14 total progeny of parental EML cells and each EML CD34 cell subset were analyzed by flow cytometry using Propidium Iodide $(n=2)$. Data are mean \pm SD. 


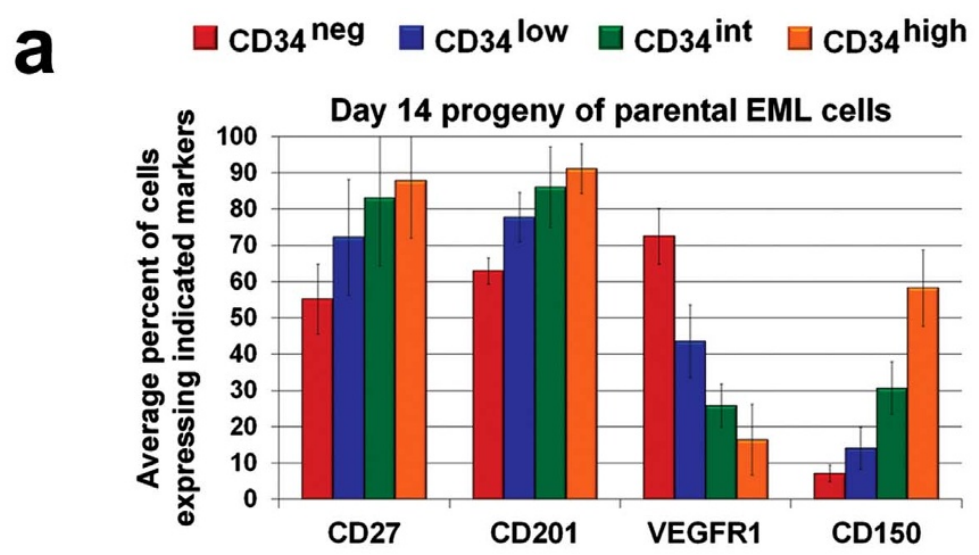

b

$\square \mathrm{CD} 34^{\text {neg }} \square \mathrm{CD} 34^{\text {low }} \square \mathrm{CD} 34^{\text {int }} \square \mathrm{CD} 34^{\text {high }}$
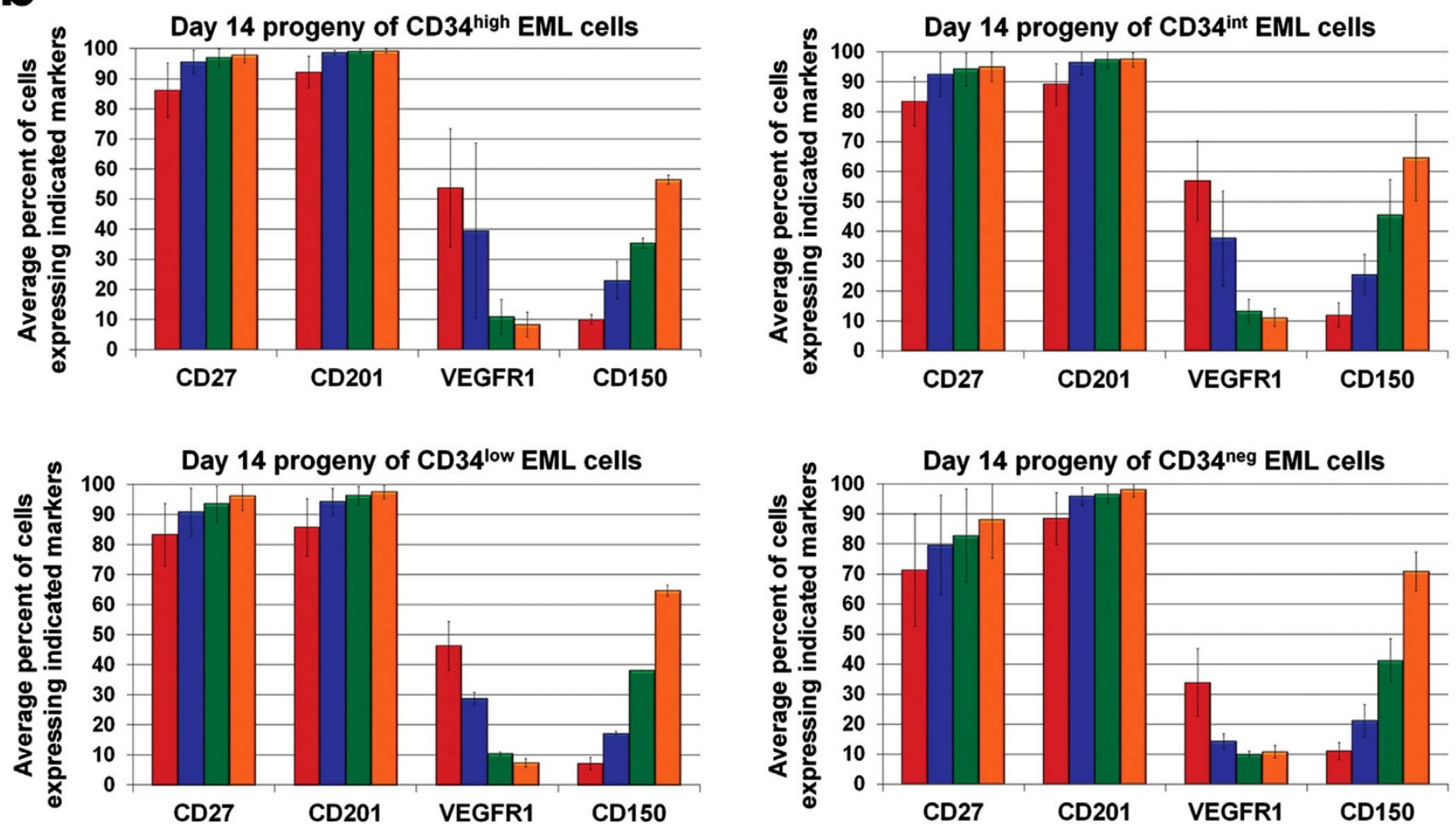

Figure $5 \mid$ Progeny of total EML cells and purified EML CD34 cell subsets consists of new EML CD34 cell subsets that recapitulate the parental expression pattern of HSC markers. Multiple independent cultures of total EML cells and purified parental CD34 $4^{\text {neg }}, \mathrm{CD} 34^{\text {low }}, \mathrm{CD} 34^{\text {int }}$ and CD34 $4^{\text {high }}$ cell subsets were maintained by serial cell passage for 14 days, and expression of several HSC markers on their day 14 progeny analyzed by flow cytometry. Total progeny of parental EML cells and each parental EML CD34 cell subset consisted of new CD $34^{\text {neg }}$, CD $34^{\text {low }}$, CD $34^{\text {int }}$ and CD $34^{\text {high }}$ cell subsets. (a) The histogram represents the results of flow cytometry analysis of CD27, VEGFR1, CD201 and CD150 HSC marker expression on new CD34 ${ }^{\text {neg }}$, CD34 ${ }^{\text {low }}$, $\mathrm{CD} 34^{\text {int }}$ and $\mathrm{CD} 34^{\text {high }}$ cell subsets generated by parental EML cells after 14 days of culture $(n=2)$. Data are mean \pm SD. (b) The histograms represent the results of flow cytometry analysis of CD27, VEGFR1, CD201 and CD150 HSC marker expression on new CD34 ${ }^{\text {neg }}$, CD34 ${ }^{\text {low }}$, CD34 $4^{\text {int }}$ and CD34 ${ }^{\text {high }}$ cell subsets generated by each of the parental EML cell susbets after 14 days of culture $(n=2)$. Data are mean $\pm \mathrm{SD}$.

the $\mathrm{CD} 34^{\text {neg }}$ and $\mathrm{CD} 34^{\text {low }}$ cells in general contained higher percentages of VEGFR $1^{+}$cells and lower percentages of $\mathrm{CD} 150^{+}$cells than $\mathrm{CD} 34^{\text {int }}$ and $\mathrm{CD} 34^{\text {high }}$ cells, while the expression pattern for $\mathrm{CD} 27$ and CD201 is opposite (Fig. 5a,b and Fig. 1d).

Although the overall pattern of HSC marker expression is preserved, the mean percentage of cells expressing CD27 and CD201 is much more homogeneous among the progeny of each subset than among parental cell subsets. Also, the $\mathrm{CD} 34^{\text {neg }}$ progeny of each parental subset contains higher percentage of VEGFR1 ${ }^{+}$cells than the parental CD $34^{\text {neg }}$ cell subset (Fig. 5b and Fig. 1d). These differences could stem from our observations (1) that the percentage of cells within each EML subset that express these markers fluctuates throughout culture (Fig. 1d), and (2) that it could take up to 3 weeks for the cumulative progeny of each CD34 cell subset to reach stable expression of these markers which is by that time very similar to typical expression of HSC markers on parental cell subsets.

Equally important, analysis of cell cycle profile of day 14 total progeny of the parental EML cells and each EML CD34 cell subset by PI staining has also shown (1) that the cell cycle profiles of the cumulative progeny of parental EML cells and each CD34 cell subset 


\section{a}
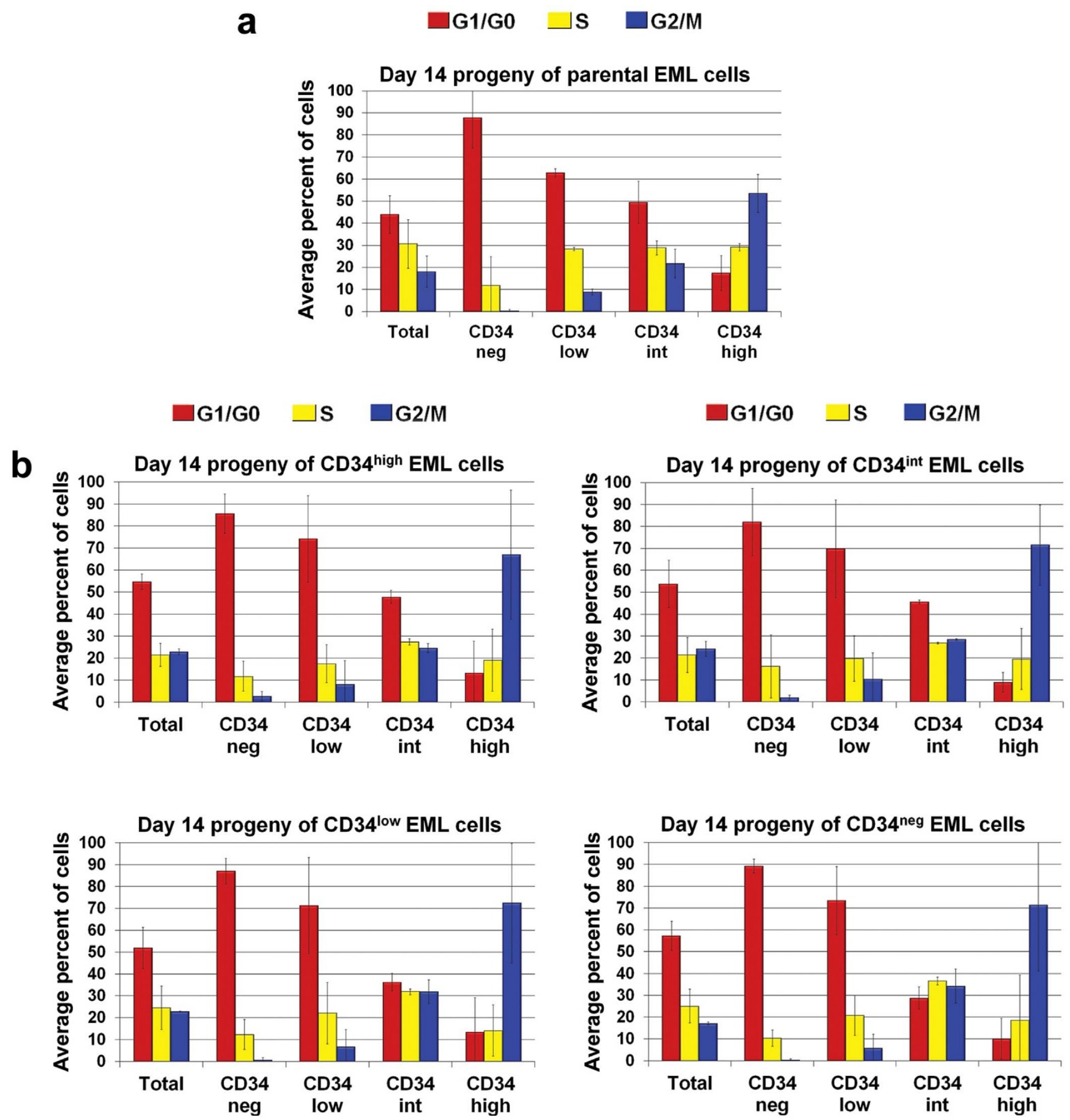

Figure 6 Progeny of total EML cells and purified EML CD34 cell subsets consists of new EML CD34 cell subsets that recapitulate the parental cell cycle profiles. Multiple independent cultures of total EML cells and purified parental CD $34^{\text {neg }}, \mathrm{CD} 34^{\text {low }}, \mathrm{CD} 34^{\text {int }}$ and $\mathrm{CD} 34^{\text {high }}$ cell subsets were maintained by serial cell passage for 14 days, and cell cycle profiles of their day 14 progeny were analyzed by flow cytometry using Propidium Iodide. Total progeny of parental EML cells and each parental EML cell subset consisted of new CD34 ${ }^{\text {neg }}, \mathrm{CD} 34^{\text {low }}, \mathrm{CD} 34^{\text {int }}$ and CD34 ${ }^{\text {high }}$ cell subsets. (a) The histogram depicts cell cycle profile analysis of new $\mathrm{CD} 34^{\text {neg }}, \mathrm{CD} 34^{\text {low }}, \mathrm{CD} 34^{\text {int }}$ and $\mathrm{CD} 34^{\text {high }}$ cell subsets generated by parental EML cells after 14 days of culture $(n=2)$. Data are mean $\pm \mathrm{SD}$. (b) The histograms depict cell cycle profile analysis of new CD $34^{\text {neg }}, \mathrm{CD} 34^{\text {low }}, \mathrm{CD} 34^{\text {int }}$ and CD $34^{\text {high }}$ cell subsets, generated by each parental EML CD34 cell subset after 14 days of culture $(n=2)$. Data are mean \pm SD.

are very similar and closely resemble cell cycle profiles of the parental population of EML cells (Fig. 4c and Fig. 2b), and (2) that the cell cycle profiles of new $\mathrm{CD} 34^{\text {neg }}, \mathrm{CD} 34^{\text {low }}, \mathrm{CD} 34^{\text {int }}$ and $\mathrm{CD} 34^{\text {high }}$ cell subsets, generated either by parental EML cells or by each parental CD34 cell subset, are very similar and closely resemble the cell cycle profiles of the parental CD34 cell subsets (Fig. 6a,b and Fig. 2b).
The interconvertible characteristics of each EML CD34 cell subset were further tested and analyzed through serial cell sorting, culture and analysis of their successive progeny over several generations. EML cells were sorted into parental CD $34^{\text {neg }}, \mathrm{CD} 34^{\text {low }}, \mathrm{CD} 34^{\text {int }}$ and CD $34^{\text {high }}$ subsets (cell purity $\geq 99 \%$ and viability $\geq 95 \%$ ) which were cultured independently for 14 days (Fig. 7a). Analysis of CD34 


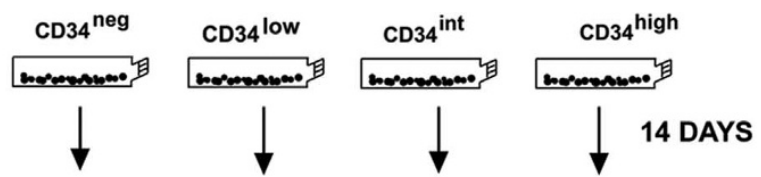

\section{b SORTING OF THE PROGENY OF PARENTAL $\mathrm{CD} 34^{\text {neg }}, \mathrm{CD} 34^{\text {low }}, \mathrm{CD} 34^{\text {int }}$ and $\mathrm{CD} 34^{\text {high }}$ CELLS INTO "PRIMARY" CELL SUBSETS}
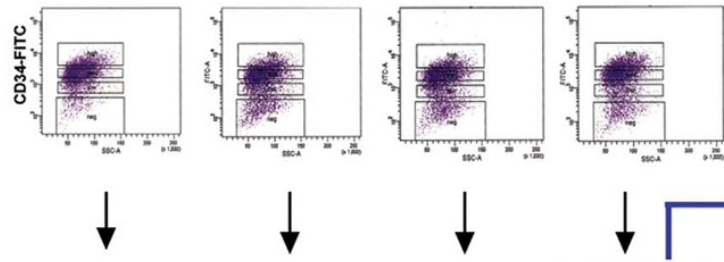

CD34 high

CD34 int

CD34 low

CD34 ${ }^{\text {neg }}$
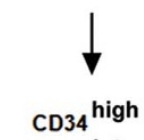

CD34 int

CD34 low

CD34 ${ }^{\text {neg }}$
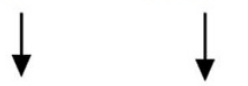

14 DAY CULTURE OF PURIFIED PRIMARY

CD $34^{\text {neg }}$, CD $34^{\text {low }}$, CD $34^{\text {int }}$ and CD $34^{\text {high }}$ CELLS

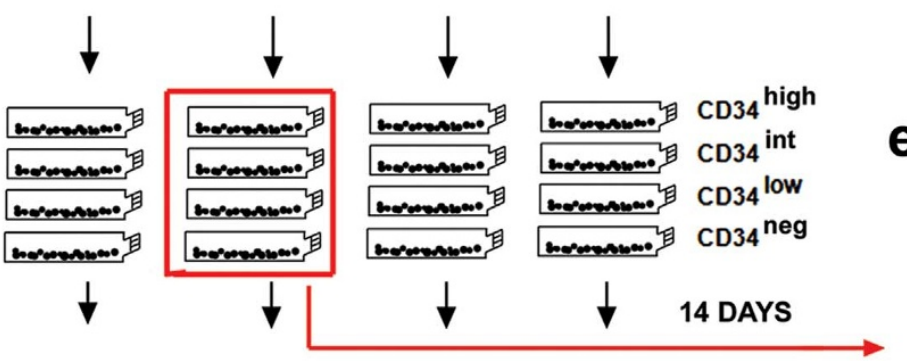

\section{FLOW CYTOMETRY ANALYSIS \\ OF CD34 EXPRESION ON THE PROGENY OF EACH PRIMARY EML CELL SUBSET}

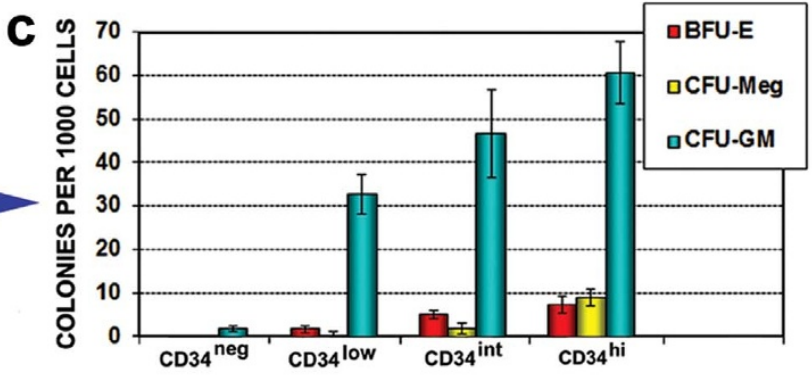

MULTILINEAGE DIFFERENTIATION OF PRIMARY CD34 ${ }^{\text {neg }}$, CD34 ${ }^{\text {low }}$, CD34 $4^{\text {int }}$ and CD34 ${ }^{\text {high }}$ CELLS GENERATED BY PARENTAL CD34 $4^{\text {high }}$ CELLS

\section{CD34 EXPRESSION ON THE PROGENY OF PRIMARY CD34 ${ }^{\text {neg }}, C_{3} 34^{\text {low }}$, CD34 $4^{\text {int }}$ and CD34 ${ }^{\text {high }}$ CELLS GENERATED BY PARENTAL CD34 ${ }^{\text {low }}$ CELLS}

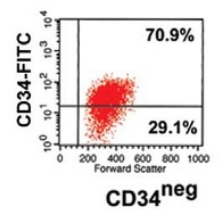

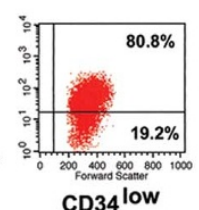

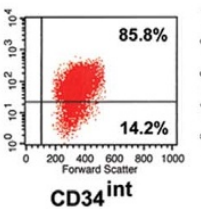

Figure 7 Serially generated EML cell subsets and their progeny retain the capacity to generate all other subsets and re-establish the parental EML cell population, while maintaining their distinct phenotypic and functional properties. (a) FACS purified parental CD34 $4^{\text {neg }}, C D 34^{\text {low }}, C D 34^{\text {int }}$ and $C D 34^{\text {high }}$ EML cell subsets (cell purity $\geq 99 \%$ and viability $\geq 95 \%$ ) were cultured for 14 days $(n=3)$. (b) Flow cytometry analysis of CD34 expression on day 14 progeny of each parental EML cell subset. Day 14 progeny of each parental cell subset was sorted into separate sets of "primary" CD34 ${ }^{\text {neg }}, \mathrm{CD} 34^{\text {low }}, \mathrm{CD} 34^{\text {int }}$ and CD $34^{\text {high }}$ subsets $(n=3)$. (c) The overall differentiation pattern of each of the primary cell subsets was analyzed using CFC asays. Shown here as an example is the differentiation pattern of the CD $34^{\text {neg }}, \mathrm{CD} 34^{\text {low }}, \mathrm{CD} 34^{\text {int }}$ and CD34 $4^{\text {high }}$ progeny of the parental CD34 ${ }^{\text {high }}$ cell subset $(\mathrm{n}=15)$. Data are shown as mean \pm SD. (d) Sets of primary CD34 ${ }^{\text {neg }}, C D 34^{\text {low }}, C D 34^{\text {int }}$ and $\mathrm{CD} 34^{\text {high }}$ cell subsets, generated by each parental cell subset, were again cultured independently for another 14 days. (e) Representative flow cytometry analysis of CD34 expression profiles on day 14 progeny of each primary EML CD34 cell subset has shown that all primary cell subsets re-established the CD34 expression profile of the parental EML cell population. Shown here as an example is CD34 expression on the progeny of primary CD34 $4^{\text {neg }}, \mathrm{CD} 34^{\text {low }}, \mathrm{CD} 34^{\text {int }}$ and CD34 $4^{\text {high }}$ cells generated by parental CD34 ${ }^{\text {low }}$ cell subset $(n=3)$.

expression on day 14 total progeny of each parental EML CD34 cell subset has again shown that each subset generated all other cell subsets and re-established the parental EML cell population (Fig. 7b). Day 14 progeny of each parental EML cell subset was sorted into separate sets of "primary" $\mathrm{CD} 34^{\text {neg }}, \mathrm{CD} 34^{\text {low }}, \mathrm{CD} 34^{\text {int }}$ and CD34 $4^{\text {high }}$ subsets (99\% purity) (Fig. 7b). CFC assays have shown that the overall differentiation patterns of each of these primary cell subsets resembled the differentiation patterns of parental cell subsets (Fig. 7c). Each of purified primary EML CD34 cell subsets was cultured independently for 14 days (Fig. 7d). Analysis of CD34 expression profile on their progeny showed that each of the primary EML CD34 cell subsets again generated all other CD34 cell subsets and re-established the broad expression range of CD34 marker typical for the parental EML cell population (Fig. 7e).

Cumulatively, these studies revealed that on a population level all EML CD34 cell subsets exhibit cell-autonomous interconvertible properties, where each subset self-renews and generates all other subsets ultimately re-establishing the complete parental population of EML cells. Furthermore, the interconversion capacity is maintained by all serially generated EML cell subsets through multiple cell generations.

Analysis of the interconversion capacity of $\mathrm{CD} 34^{\text {neg }}, \mathrm{CD} 34^{\text {low }}$, CD34 $4^{\text {int }}$ and CD34 ${ }^{\text {high }}$ single cell clones. Although our data clearly 
show that the CD34 $4^{\text {neg }}, \mathrm{CD} 34^{\text {low }}, \mathrm{CD} 34^{\text {int }}$ and CD34 $4^{\text {high }}$ EML cell subsets contain cells with interconversion capacity, the question remained whether all or only a fraction of cells in each CD34 subset have that capacity.

The instructions for maintenance of EML cell line (obtained directly from Dr. Tsai) ${ }^{30}$ and our own long-term experience show that EML cells grow optimally when maintained at a concentration of $\sim 2 \times 10^{5}$ cells $/ \mathrm{ml}$. Culturing EML cells below the concentration of $0.5 \times 10^{5}$ cells $/ \mathrm{ml}$ slows down the cell growth, increases apoptosis and leads to population drift and culture collapse. When cultured as single cells in 96-well plates only a fraction of EML cells $(<20 \%)$ generated some progeny $(\sim 10$ to $<500$ cells) which rarely expanded to the level necessary for proper flow cytometry analysis. Similarly, only a small percentage of total EML cells and purified CD $34^{\text {neg, }}$, CD $34^{\text {low }}, \mathrm{CD} 34^{\text {int }}$ and CD34 $4^{\text {high }}$ EML cells forms single cell-derived undifferentiated blast colonies (CFU-Blast) ${ }^{30}$ when plated at a low cell density $\left(10^{3}\right.$ cells $\left./ \mathrm{ml}\right)$ into methylcellulose cultures supplemented with recombinant SCF (Supplementary Fig. S8). Although these colonies can be extracted and cultured in EML media, the majority of extracted CFU-Blast colonies do not expand sufficiently in liquid cultures.

In an attempt to analyze interconvertibility of EML CD34 cell subsets at a single cell level, we undertook a different experimental approach. The CD $34^{\text {neg }}, \mathrm{CD} 34^{\text {low }}, \mathrm{CD} 34^{\text {int }}$ and CD $34^{\text {high }}$ cell subsets were purified from GFP-expressing EML cells and single $\mathrm{GFP}^{+}$cells from each subset were cultured together with wild type $\mathrm{GFP}^{-} \mathrm{EML}$ cells as "support" cells in a mixed culture system.

$\mathrm{GFP}^{+}$EML cells were generated by transduction of wt EML cells with murine stem cell virus (MSCV)-based bicistronic retroviral vector, with IRES driving expression of GFP. EML cells were transduced at several different MOI (transduction efficiency of 70-85\%), and 72 hours after transduction, $\mathrm{GFP}^{+}$EML cells were purified by sorting (Supplementary Fig. S9a). Multiple $\mathrm{GFP}^{+}$EML cell clones were generated, expanded and early passages cryopreserved. All $\mathrm{GFP}^{+}$EML cell clones have shown long-term (>6 months), stable expression of GFP, and displayed the same growth characteristics as wt EML cells (data not shown).

Flow cytometry analysis did not reveal any significant differences in the expression pattern of c-kit, Sca-1, Flk-2 and CD34 markers between wt EML cells and $\mathrm{GFP}^{+}$EML cells, (Supplementary Fig. S9b,c and Fig. 1a). The analysis of the cell cycle status with PI has reproducibly shown that the percentage of wt EML cells and GFP ${ }^{+}$ EML cells in G0/G1 and S/G2/M phases was almost identical (Supplementary Fig. S9d and Fig. 2b). In the hematopoietic CFC assays wt EML and GFP ${ }^{+}$EML cells displayed almost identical multilineage differentiation capacity (Supplementary Fig. S9e). These results indicate that transduction with MSCV and GFP expression had no effects on the HSC marker expression pattern, cell cycle profile and differentiation capacity of $\mathrm{GFP}^{+}$EML cells. Moreover, $\mathrm{GFP}^{+}$EML cells show interconvertible properties identical to wt EML cells (data not shown).

The $\mathrm{CD} 34^{\text {neg }}, \mathrm{CD} 34^{\text {low }}, \mathrm{CD} 34^{\text {int }}$ and $\mathrm{CD} 34^{\text {high }}$ cell subsets were purified from GFP + EML cells by cell sorting (Fig. 8a). The high purity cells from each subset were deposited at a concentration of $\leq 1$ cell/well into individual round bottom wells within 96-well plates; with each well containing $1 \times 10^{4}$ wt $\mathrm{GFP}^{-}$EML cells in $100 \mu \mathrm{l}$ of EML media (Fig. 8a). The cells in each well were expanded by passaging the cell progeny sequentially into 24 -well plates, 6 -well plates, T25 culture flasks and finally into T75 culture flasks.

Cell aliquots from each of these mixed cultures were analyzed by flow cytometry to identify all cultures containing $\mathrm{GFP}^{+}$progeny from single CD $34^{\text {neg }}, \mathrm{CD} 34^{\text {low }}, \mathrm{CD} 34^{\text {int }}$ and CD34 $4^{\text {high }}$ cells (Fig. $8 \mathrm{a}$ ). In these experiments $\sim 21 \%$ of single $\mathrm{GFP}^{+} \mathrm{CD} 34^{\text {neg }}$ cells, $\sim 28 \%$ of single $\mathrm{GFP}^{+} \mathrm{CD} 34^{\text {low }}$ cells, $\sim 48 \%$ of single $\mathrm{GFP}^{+} \mathrm{CD} 34^{\text {int }}$ cells and $\sim 57 \%$ of single $\mathrm{GFP}^{+} \mathrm{CD} 34^{\text {high }}$ cells generated various levels of progeny (Fig. 8b).
$\mathrm{GFP}+$ progeny of each $\mathrm{CD} 34^{\text {neg }}, \mathrm{CD} 34^{\text {low }}, \mathrm{CD} 34^{\text {int }}$ and $\mathrm{CD} 34^{\text {high }}$ single cell clone was purified from mixed cultures by cell sorting and cultured independently for 14 days to expand the cells for flow cytometry analysis (Fig. 8a). While the progeny of the CD34 $4^{\text {int }}$ and $\mathrm{CD} 34^{\text {high }}$ single cell clones expanded very well, the progeny of the CD $34^{\text {neg }}$ and CD $34^{\text {low }}$ single cell clones did not expand efficiently to generate enough cells for proper flow cytometry analysis.

Nevertheless, flow analysis of the progeny of multiple CD $34^{\text {int }}$ and CD34 ${ }^{\text {high }}$ single cell clones has shown that each clone generated all other CD34 cell subsets and re-established the broad expression pattern of CD34 marker typical for complete parental EML cell population (Fig. 8c,d and data not shown).

\section{Discussion}

To gain further insight into the heterogeneity and interconvertibility of multipotent hematopoietic cells, we analyzed in more depth the heterogeneity and interconvertible properties of cells within the multipotent cell line EML. The expression pattern of a panel of HSC markers revealed an extensive phenotypic heterogeneity among EML cells, which resembles heterogeneous expression of various markers on HSCs and their subsets ${ }^{6,15,42-49}$. Using broad range of expression of the CD34 marker EML cells can be reproducibly divided into $\mathrm{CD} 34^{\text {neg }}, \mathrm{CD} 34^{\text {low }}, \mathrm{CD} 34^{\text {int }}$ and $\mathrm{CD} 34^{\text {high }}$ cell subsets. Remarkably, all EML CD34 cell subsets are phenotypically quite heterogeneous as well, and display distinct expression pattern of various HSC markers (Sca-1, CD27, CD150, CD201, VEGFR1). In that regard, each EML CD34 cell subset can be further divided into distinct subpopulations based on the co-expression patterns of various HSC markers.

Functional characterization of EML CD34 cell subsets has revealed that they display distinct multilineage differentiation capacity, cell cycle profiles, CFSE labeling profile and proliferation kinetics when compared against each other. Moreover, the immunophenotypic and functional blueprints of each EML cell subset suggest a closer association between the $\mathrm{CD} 34^{\text {neg }}$ and $\mathrm{CD} 34^{\text {low }}$ cell subsets on one end and the CD34 ${ }^{\text {int }}$ and CD34 ${ }^{\text {high }}$ cell subsets on the other end.

By establishing phenotypic and functional signatures of EML CD34 cell subsets our studies have revealed even more extensive cellular heterogeneity and complexity within EML cell line, and support the notion that EML cell line consists of multiple distinct cell subsets.

The microarray analysis and comparison of hematopoietic transcriptional signatures in CD $34^{\text {neg }}$ EML cells and combined CD $34^{\text {int }}$ and $\mathrm{CD} 34^{\text {high }}$ subsets did not reveal significant differences in the expression of the majority of (1) genes important for overall hematopoiesis and HSC maintenance and function, (2) hematopoietic cell surface markers, receptors and adhesion molecules, and (3) genes associated with erythroid, megakaryocytic, myeloid and lymphoid lineage specification and development $t^{50-52}$. These results are very similar to findings of earlier studies, which reported that expression levels of most genes are quite similar in Sca- $1^{-} \mathrm{CD} 34^{-}$and Sca$1^{+} \mathrm{CD} 34^{+}$EML cells ${ }^{34,41}$.

Previously, Sca- $1^{\text {low }}$ EML cells were found to express significantly higher levels of GATA-1 and lower levels of PU.1 transcript and protein than Sca- $1^{\text {high }}$ EML cells, although at the single cell level the Sca- $1^{\text {low }}$ EML cells are quite heterogeneous for GATA- 1 expression $^{32,34,41}$. Division of Sca- $1^{\text {low }}$ EML cells into CD34- and CD34 ${ }^{+}$ subsets revealed that $\leq 80 \%$ of Sca ${ }^{\text {low }} \mathrm{CD} 34^{-}$EML cells and less than $5 \%$ of Sca ${ }^{\text {low }} \mathrm{CD} 34^{+}$cells express GATA- $1^{34}$.

Our studies have shown that expression of GATA-1 transcript is the highest in the CD $34^{\text {neg }}$ and $\mathrm{CD} 34^{\text {low }}$ cell subsets and significantly lower in the CD $34^{\text {int }}$ and CD $34^{\text {high }}$ subsets. In contrast, the expression of PU.1 transcript is the highest in CD $34^{\text {high }}$ subset and is significantly lower in the $\mathrm{CD} 34^{\text {int }}$, $\mathrm{CD} 34^{\text {low }}$ and $\mathrm{CD} 34^{\text {neg }}$ subsets.

Western analysis has revealed that the expression of GATA-1 protein is higher in the $\mathrm{CD} 34^{\text {neg }}$ and $\mathrm{CD} 34^{\text {low }}$ cells, while the express- 

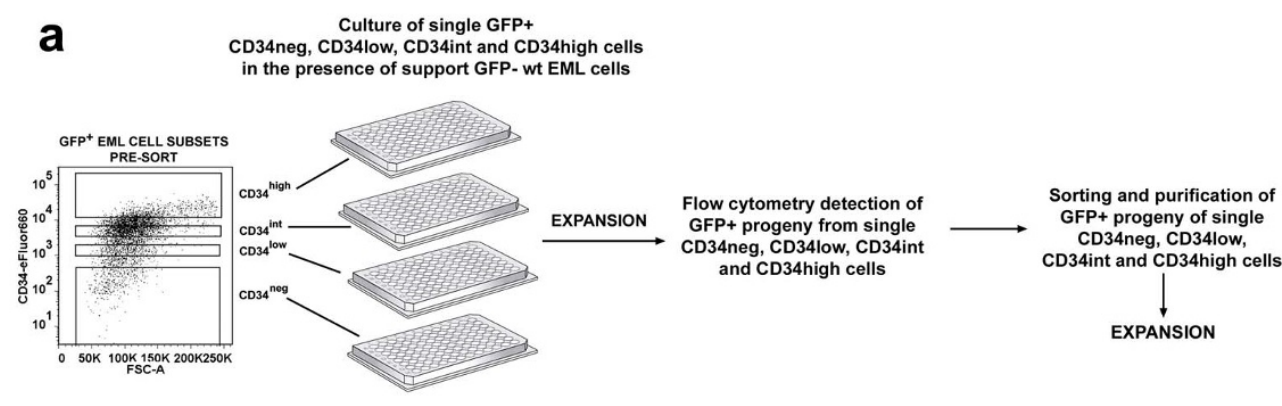
and CD34high cells

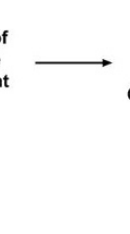

EXPANSION

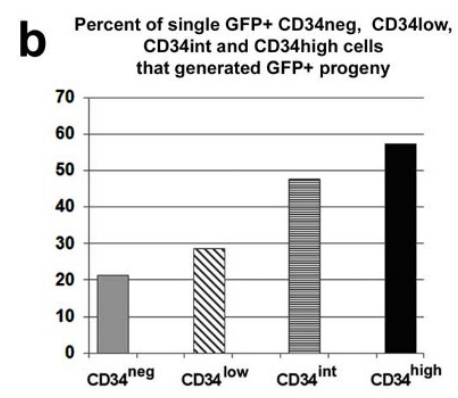

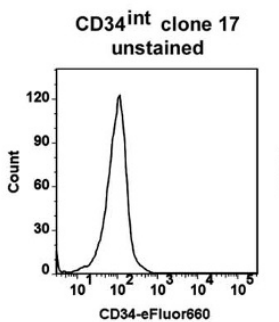
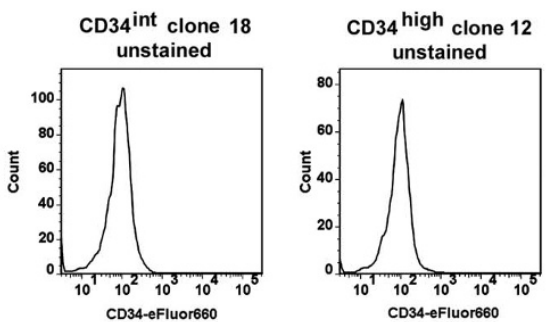

CD34-eFluor660
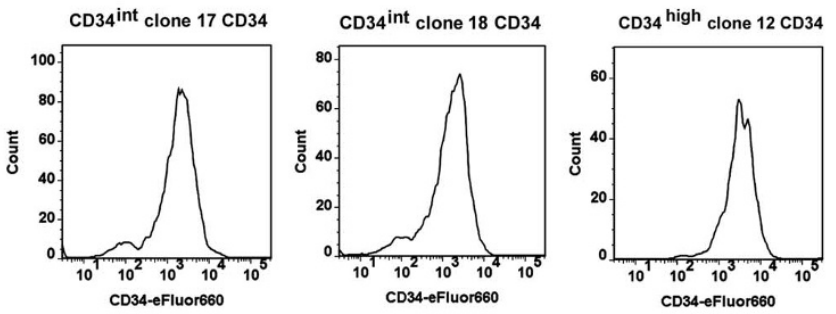
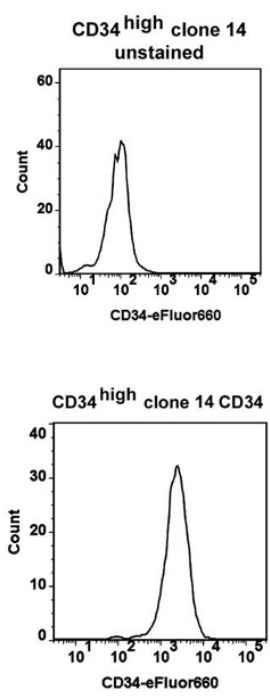
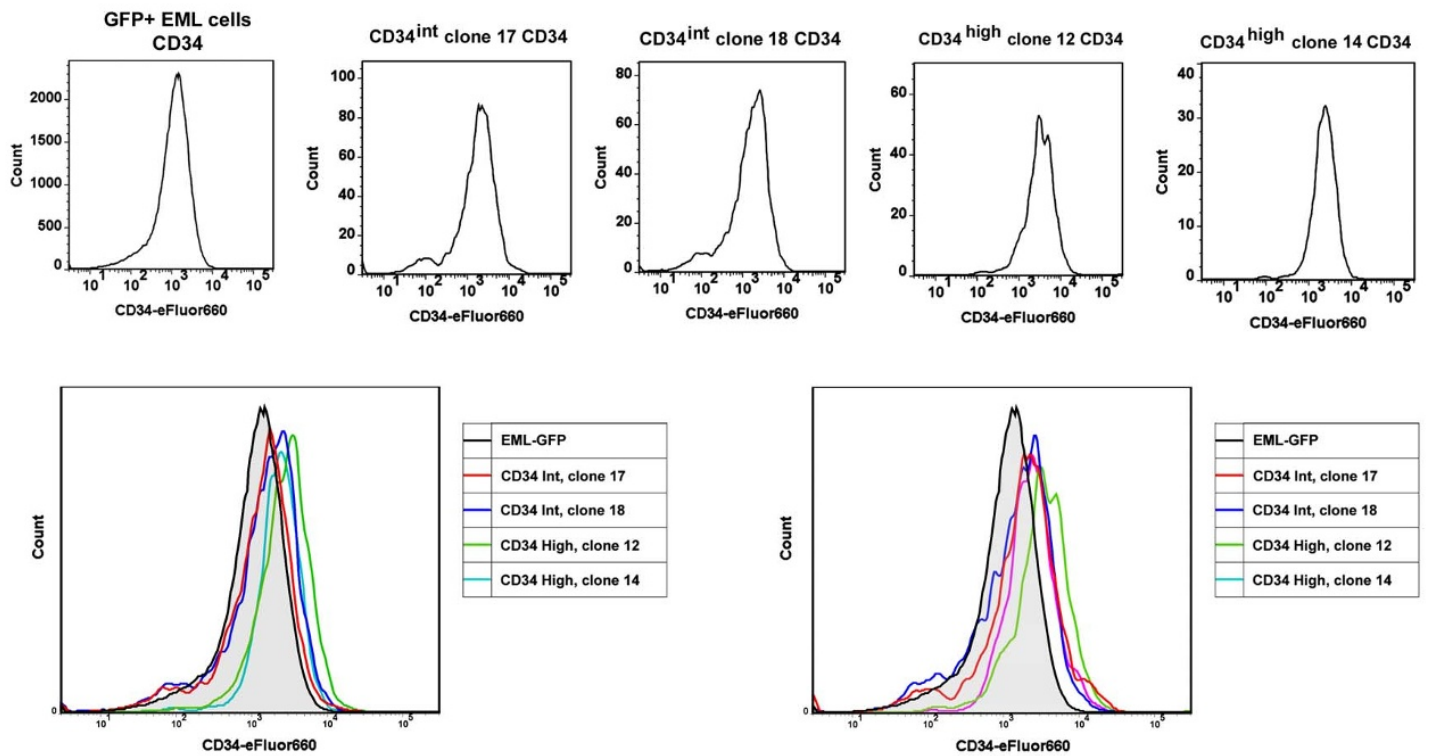

Figure $8 \mid$ Analysis of interconversion capacity of CD34 ${ }^{\text {neg }}, \mathrm{CD} 34^{\text {low }}, \mathrm{CD} 34^{\text {int }}$ and $\mathrm{CD} 34^{\text {high }}$ single cell clones. (a) Experimental approach to analyze interconversion capacity of $\mathrm{GFP}^{+} \mathrm{CD} 34^{\text {neg }}, \mathrm{CD} 34^{\text {low }}, \mathrm{CD} 34^{\text {int }}$ and $\mathrm{CD} 34^{\text {high }}$ single cell clones using mixed culture system with wild type GFP ${ }^{-} \mathrm{EML}$ cells as "support" cells. (b) Frequency of CD $34^{\text {neg }}, \mathrm{CD} 34^{\text {low }}, \mathrm{CD} 34^{\text {int }}$ and $\mathrm{CD} 34^{\text {high }}$ single cells that generated $\mathrm{GFP}^{+}$cell progeny in mixed culture system. (c) Representative flow cytometry density plots showing the CD34 expression pattern on parental GFP + EML cells and the progeny of two independently generated CD $34^{\text {int }}$ and CD34 $4^{\text {high }}$ single cell clones, showing re-establishment of the broad expression range of CD34 marker typical for parental EML cell population $(n=3)$. (d) A representative overlay of the expression range of CD34 marker on GFP+ parental EML cells and the progeny of two different subclones of independently generated CD $34^{\text {int }}$ and CD $34^{\text {high }}$ single cell clones $(n=6)$.

ion of PU.1 protein is the highest in the CD34 ${ }^{\text {high }}$ and CD34 $4^{\text {int }}$ cells. However, the differences in the expression of GATA-1 protein between EML CD34 cell subsets were not as prominent as the ones observed between Sca- $1^{\text {low }}$, Sca- $1^{\text {med }}$ and Sca- $1^{\text {high }}$ EML cells, and Sca$1^{\text {low }} \mathrm{CD}^{-} 4^{-}$and Sca $1^{\text {low }} \mathrm{CD} 34^{+} \mathrm{EML} \mathrm{cells}^{32,34}$.

That dissimilarity is most likely due to differences in the cellular composition of Sca- $1^{\text {low }}$, Sca- $1^{\text {med }}, \mathrm{Sca}-1^{\text {high }}, \mathrm{Sca}-1^{\text {low }} \mathrm{CD} 34^{-}$and Sca $1^{\text {low }}$ CD34 ${ }^{+}$EML cells on one end and EML CD34 cell subsets on the other. For example, the CD34 ${ }^{\text {neg }}$ cell subset encompasses the cells displaying the full range of Sca-1 expression (i.e. Sca- $1^{\text {neg }}$, Sca$1^{\text {low }}$, Sca- $1^{\text {med }}$ and Sca- $1^{\text {high }}$ cells) (Supplementary Fig. S4), and contains previously analyzed Sca- $1^{\text {low }}, \mathrm{Sca}-1^{\text {med }}, \mathrm{Sca}-1^{\text {high }}, \mathrm{Sca}-1^{\text {low }} \mathrm{CD} 34^{-}$ and Sca ${ }^{\text {low }} \mathrm{CD} 34^{+}$EML cells. Thus, the level of GATA-1 expression found in $\mathrm{CD} 34^{\text {neg }}$ cell population is an average of different levels of
GATA-1 expression found previously in various Sca-1 EML cell subsets.

Transcription factor $\mathrm{C} / \mathrm{EBP} \alpha$ controls developmental fate of multipotent hematopoietic cells by promoting myeloid and inhibiting erythroid differentiation ${ }^{55,56}$. Both earlier and our own microarray studies indicated that the expression of $\mathrm{C} / \mathrm{EBP} \alpha$ transcript is (1) higher in Sca1 ${ }^{+} \mathrm{CD} 34^{+}$EML cells than in Sca1 ${ }^{-} \mathrm{CD} 34^{-} \mathrm{EML} \mathrm{cells}^{41}$, and (2) higher in CD34 $4^{\text {high }}$ and CD34 $4^{\text {int }}$ cells than in CD34 $4^{\text {neg }}$ and CD34 ${ }^{\text {low }}$ cells (Fig. 3). Although our qRT-PCR analysis revealed highly significant difference in the expression of $\mathrm{C} / \mathrm{EBP} \alpha$ transcript between $\mathrm{CD} 34^{\text {high }}$ and CD $34^{\text {int }}$ cells on one end and CD $34^{\text {neg }}$ and $\mathrm{CD} 34^{\text {low }}$ cells on the other end, there was no significant difference in the expression of $\mathrm{C} / \mathrm{EBP} \alpha$ protein between all EML CD34 cell subsets (Fig. 3). 
The observed differences between the expression levels of GATA1 and $\mathrm{C} / \mathrm{EBP} \alpha$ transcripts and proteins in EML CD34 subsets could be the consequence of an unequal rate of GATA- 1 and $\mathrm{C} / \mathrm{EBP} \alpha$ protein translation or differential rate of protein degradation in these cell subsets.

Cumulatively, these studies have discovered differential expression of some of the key transcriptional regulators of lineage specification and commitment between EML CD34 cell subsets, and the grouping of $\mathrm{CD} 34^{\text {neg }}$ and $\mathrm{CD} 34^{\text {low }}$ cells versus CD34 $4^{\text {high }}$ and CD34 $4^{\text {int }}$ cells in terms of their expresion pattern of lineage-associated transcription factors.

Moreover, these results reaffirm the notion that EML CD34 cell subsets are heterogeneous and encompass cells in different stages of lineage specification and commitment. In that regard the CD34 $4^{\text {neg }}$ EML cell subset is functionally heterogeneous and consists of several cell subpopulations, including a subpopulation of cells that express high levels of GATA-1, are more erythroid committed but exhibit low differentiation rate into erythroid and myeloid lineages.

On the other end, the expression pattern of lineage-associated transcription factors and more efficient diffrentiation into myeloid and erythroid lineages suggest that the $\mathrm{CD} 34^{\text {int }}$ and $\mathrm{CD} 34^{\text {high }}$ subsets contain cells that are either oligopotent and give rise to multiple lineages in response to cytokines or are committed only to erythroid or myeloid lineages.

Using phenotypic and functional signatures of EML CD34 cell subsets as a platform, we interrogated their maintenance during multiple cell generations. Temporal analysis of the primary progeny of each purified EML CD34 cell subset established that as a cell population each CD34 subset exhibits cell-autonomous interconvertible properties, and contains cells that both self-renew and generate other cell subsets, ultimately re-establishing complete parental EML cell population (Supplementary Fig. S10a).

Further testing of interconvertible characteristics of each EML CD34 cell subset through serial cell sorting, culture and analysis of their successive progeny over several generations demonstrated that all sequentially generated CD34 cell subsets maintain their interconvertible properties and the capacity to self-renew, generate all other CD34 subsets and re-establish the parental EML cell population, while maintaining cell subset-specific phenotypic and functional features (Supplementary Fig. S10b). These findings support the view that EML cell line consists of multiple interconvertible cell subsets which co-exist in a dynamic but stable equilibrium through multiple cell generations.

Equally important, perpetual maintenance of interconvertible EML cell subsets in the absence of cellular and molecular components of BM HSC niches ${ }^{59}$ (with an exception of SCF), infers that similar to intrinsically regul ated interconvertibility of ES cell subsets $^{1-3,20,21}$, the dynamic equilibrium of interconvertible EML cell subsets is homeostatically maintained and regulated at least in part by currently unknown cell-intrinsic mechanisms.

While all EML CD34 cell subsets clearly contain cells with interconversion capacity, the question remained whether all or only a fraction of cells in each subset have that capacity.

Chang et al. used methylcellulose cloning method to generate random single cell-derived clones from total EML cells that expressed varying levels of Sca-1. Over a period of 8 weeks these clones regenerated the original broad expression profile of Sca-1, typical for EML cell line ${ }^{32}$. Pina et al. sorted single cells from Sca$1^{\text {lo }}, \mathrm{Sca} 1^{\text {lo }} \mathrm{CD} 34^{-}$and Sca $1^{\text {lo }} \mathrm{CD} 34^{+}$subsets into 96 -well plates and analyzed their so called culture-reconstituting potential over a period of several days. In that study $17 \%$ of Sca- $1^{\text {lo }}, 2.5 \%$ of Sca $1^{\text {lo }} \mathrm{CD} 34^{-}$ and $35 \%$ of Sca $1^{\text {lo }} \mathrm{CD} 34^{+}$cells generated more than 100 cells, which supposedly also reconstituted broad Sca-1 expression ${ }^{34}$.

Using a mixed culture system we generated multiple CD $34^{\text {neg, }}$ $\mathrm{CD} 34^{\text {low }}, \mathrm{CD} 34^{\text {int }}$ and $\mathrm{CD} 34^{\text {high }}$ single cell clones. However, we were able to sufficiently expand only the progeny of CD $34^{\text {int }}$ and CD $34^{\text {high }}$ single cell clones, which exhibited interconversion capacity by generating all other EML CD34 cell subsets and re-establishing the broad expression pattern of CD34 marker typical for complete parental EML cell population.

Our studies are clearly showing that on a cell population level both $\mathrm{CD} 34^{\text {neg }}$ and $\mathrm{CD} 34^{\text {low }}$ cell subsets exhibit interconvertible properties. However, the culture of purified CD $34^{\text {neg }}$ and CD $34^{\text {low }}$ cells has consistently shown their delayed kinetics of regenerating the parental EML cell population. Moreover, that kinetics in mixed culture with other cell subsets being present remains to be determined. Thus, although the progeny of $\mathrm{CD} 34^{\text {neg }}$ and $\mathrm{CD} 34^{\text {low }}$ single cell clones did not expand sufficiently to determine their capacity to regenerate parental EML cell population, that outcome does not mean that single cells from these subsets do not possess interconvertible properties.

Collectively, our findings further highlight the phenotypic and functional heterogeneity of EML cell subsets, and bring additional insight into the characteristics and extent of EML cell interconvertibility. In addition, together with previous studies, our results further emphasize the biological relevance of EML cell line as a unique experimental model to study the process of interconversion and cellintrinsic and extrinsic pathways that regulate interconversion among multipotent hematopoietic cells.

While the previous and our studies demonstrated interconversion capacity of EML cells at a single cell level to a varying extent, the actual identity and phenotypic and functional features of these cells remain to be fully elucidated.

Purification of specific cell subpopulations with defined immunophenotypes within each EML CD34 cell subset now allows identification of exact cell fractions in each subset that have interconversion capacity. In that regard, the cellular barcoding ${ }^{60}$ of phenotypically defined EML cell populations with documented interconversion capacity could enable more precise in vitro tracking of the progeny of single cells, and help to more accurately analyze the process of interconversion in a mixed culture system with multiple subsets present at the same time. This approach could also provide a platform for elucidating intrinsic molecular mechanisms regulating the process of interconversion between different states.

Better defined heterogeneity of EML cell subsets, purification of specific cell subpopulations based on their immunophenotypes, and the molecular analysis on a single cell level ${ }^{15}$ could provide a high resolution insight into the developmental and lineage commitment stages, and developmental hierarchy of cells composing each EML cell subset.

\section{Methods}

Cell lines and cell culture. The Stem Cell Factor (SCF)-dependent EML cell line was kindly provided by Dr. Steve Collins (Fred Hutchinson Cancer Research Center, Seattle, WA). EML cells were maintained in IMDM with L-glutamine (Gibco), and supplemented with 20\% (vol/vol) equine serum (Hyclone), 1\% Penicillin/

Streptomycin (Sigma) and $10 \%(\mathrm{vol} / \mathrm{vol})$ conditioned media from the BHK/MKL cell line (constitutively expressing recombinant soluble SCF) as previously described ${ }^{31,37}$ EML cells were maintained at a density of $\sim 2 \times 10^{5}$ cells $/ \mathrm{ml}$, and were passaged every other day. The BHK/MKL cell line was maintained in DMEM with L-glutamine (Gibco), 10\% fetal bovine serum (Hyclone), and 1\% Penicillin/Streptomycin (Sigma). Conditioned media was collected from confluent BHK/MKL cell cultures at 48 and 96 hours, centrifuged at $1200 \mathrm{rpm}$ for 10 minutes, filtered through a $0.45 \mu \mathrm{m}$ membrane (Nalgene) and stored at $-20^{\circ} \mathrm{C}$.

Flow cytometry analysis and cell sorting. EML cells were harvested, washed with phosphate buffered saline (PBS), and incubated with antibodies at concentrations of $1-2 \mu \mathrm{g}$ per $10^{6}$ cells in $100 \mu \mathrm{l}$ of PBS for $40 \mathrm{~min}$ on ice, followed by double wash in PBS. Centrifugation steps were carried out at $1200 \mathrm{rpm}$ for $10 \mathrm{~min}$ at $4^{\circ} \mathrm{C}$. The cells were analyzed live or after fixation in $10 \%$ neutral buffered formalin. The following antibodies were used: IgG2a and IgG2b isotype controls (eBioscience), anti-c-kit APC (eBioscience, clone 2B8), anti-Sca-1 PE-Cy7 (eBioscience, clone D7), anti-Flk-2 PE (eBioscience, clone A2F10), anti-CD49b PE-Cy7 (eBioscience, clone DX5), antiCD34 FITC (eBioscience, clone RAM34), anti-CD34 eFluor660 (eBioscience, clone RAM34), anti-CD150 APC (eBioscience, clone 9D1), anti-CD201 AlexaFluor647 (eBioscience, clone mRCR-16), anti-VEGFR1 APC (R\&D Systems, clone 141522) and anti-CD27 PE-Cy7 (eBioscience, clone LG.7F9). Before labeling of cells with 
multiple antibodies, different fluorochromes were checked for compatibility and compensation utilizing the BD Fluorescence Spectrum Viewer. The expression of various markers on cells was analyzed on BD LSR II or BD LSRFortessa flow cytometers (BD Biosciences) using the live cell gate. Flow cytometry data were analyzed with FlowJo software (Tree Star). EML cells and cell subsets were sorted on a FACSAria II sorter (BD Biosciences). Only the cells from sorts yielding the highest cell purity $(>99 \%)$ and viability $(>95 \%)$ were used for experiments.

Cell cycle analysis and proliferation kinetics. The cell cycle profile of total EML cells and purified CD $34^{\text {neg }}, \mathrm{CD} 34^{\text {low }}, \mathrm{CD} 34^{\text {int }}$ and CD $34^{\text {high }}$ EML cell subsets was analyzed by Propidium Iodide (PI), Hoechst 33342, and Ki-67/7-AAD staining. For staining with PI (BIOTIUM) the cells were resuspended in cold 70\% ethanol, washed in PBS, treated with $0.1 \mathrm{mg} / \mathrm{ml} \mathrm{RNase} A$, and incubated with $0.1 \mu \mathrm{g} / \mu \mathrm{l}$ PI. For staining with Hoechst 33342 (SIGMA) the cells were resuspended in cold PBS/1\% formaldehyde, and incubated with $5 \mu \mathrm{g} / \mathrm{ml}$ Hoechst at $37^{\circ} \mathrm{C}$ for 15 minutes. For analysis of Ki-67 expression, the EML cells were first labeled with anti-CD34 FITC antibody. Staining of labeled EML cells with Ki-67-eFluor450 (eBioscience, clone B56) followed the eBioscience Protocol B for Staining Intracellular Antigens for Flow Cytometry (http:// www.ebioscience.com/media/pdf/best-protocols/staining-intracellular-antigensfor-flow-cytometry.pdf), utilizing the Foxp3/Transcription factor staining buffer set (eBioscience), followed by addition of $1: 100 \mu \mathrm{l}$ of 7-AAD (BioLegend) in PBS.

To examine their proliferation kinetics, total EML cells and EML cell subsets were labeled with CFSE (Carboxyfluorescein diacetate succinimidyl ester) (Invitrogen) by adding $1.5 \mu \mathrm{M}$ CFSE in $1 \mathrm{ml}$ of $0.1 \% \mathrm{FBS} / 1 \mathrm{X}$ PBS for 8 minutes at room temperature, followed by addition of $1 \mathrm{ml}$ of warm FBS and 10 minute incubation in $37^{\circ} \mathrm{C}$ water bath. The cells were washed 3 times in $2 \%$ FBS/1X PBS and placed in culture. The division of CFSE labeled EML cells was evaluated at 24 hour time points for 5 days. Aliquots of CFSE labeled cells at each time point were incubated with anti-CD34 eFluor660 antibody (eBioscience) as described. At each time point only the viable cells, as determined by staining with PI or LIVE/DEAD ${ }^{\circledR}$ Fixable Yellow Dead Cell Stain Kit (Invitrogen), were analyzed.

Hematopoietic colony-forming unit assays. To assess their multilineage differentiation capacity, total EML cells and purified CD $34^{\text {neg }}, \mathrm{CD} 34^{\text {low }}, \mathrm{CD} 34^{\text {int }}$ and CD34 ${ }^{\text {high }}$ EML cell subsets were plated in $2 \mathrm{ml}$ of $0.3 \%$ low melting temperature agarose (SeaPlaque, Cambrex) with 2X IMDM (Gibco), 20\% heat inactivated equine serum (Hyclone) and 10\% SCF-conditioned medium in replicate 6-well plates $\left(10^{3} \text { cells/well }\right)^{37,38}$. The media was supplemented with: $0.1 \mathrm{ng} / \mathrm{ml}$ of recombinant mouse interleukin 3 (IL-3) (R\&D Systems) for generation of granulocytemacrophage colony forming units (CFU-GM); $8 \mathrm{U} / \mathrm{ml}$ of recombinant human erythropoietin (Epo) (Ortho Biotech) for generation of burst-forming erythroid units (BFU-E); and $3 \mathrm{ng} / \mathrm{ml}$ of recombinant mouse Thrombopoietin (Tpo) (R\&D Systems) for generation of megakaryocyte colony forming units (CFU-Meg). Cultures were maintained at $37^{\circ} \mathrm{C}, 5 \% \mathrm{CO}_{2}$ for 7-10 days. The BFU-E, CFU-GM and CFU-Meg colonies were counted 7-10 days after plating. Data from multiple independent experiments $(n=15)$ are shown as mean \pm standard deviation (SD).

Microarray expression analysis. To examine molecular differences between EML cell subsets we analyzed the transcriptomes in three separately purified samples of CD $34^{\text {neg }}$ cells and combined CD $34^{\text {int }}$ and CD $34^{\text {high }}$ subsets, refrerred to in the text as $\mathrm{CD}_{3}{ }^{+}$cells. The microarray expression analysis was performed by Ocean Ridge Biosciences (ORB, Palm Beach Gardens, FL) using Agilent mouse microarrays. The mRNA samples were prepared from total EML cells and purified CD $34^{\text {neg }}$ and CD $34^{+}$ EML cells using Micro-FastTrack ${ }^{\mathrm{TM}} 2.0$ mRNA and mRNA DIRECT Isolation Kits (Life Technologies). Ocean Ridge Biosciences performed additional purification of mRNA, sample labeling, microarray hybridization and data analysis. The results were provided by ORB in Log2 transformed form and are presented as mean \pm s.d. $(n=3)$. The $\leq 1.5$-fold difference in expression was not considered significant. To identify differences in the hematopoietic transcriptomes between EML CD34 cell subsets we specifically examined the expression of (1) genes important for overall hematopoiesis and HSC maintenance and function, (2) hematopoietic cell surface markers, receptors and adhesion molecules, and (3) genes associated with erythroid, megakaryocytic, myeloid and lymphoid lineage specification and development.

Quantitative real-time reverse transcription PCR analysis. mRNA was isolated using the Micro-FastTrack ${ }^{\mathrm{TM}} 2.0$ mRNA and mRNA DIRECT Isolation Kit (Life Technologies). Equal amount of mRNA from each cell sample was reverse transcribed using High Capacity cDNA Reverse Transcription Kit (Applied Biosystems). Quantitative RT-PCR reactions ( $\mathrm{qRT}-\mathrm{PCR}$ ) reactions were performed in an Agilent Technologies Stratagene Mx3005P for 40 cycles $\left(95^{\circ} \mathrm{C}\right.$ for 30 seconds, $57-62^{\circ} \mathrm{C}$ for 1 minute, and $72^{\circ} \mathrm{C}$ for 1 minute). The specificity of PCR products was verified by melting curve analysis and by running qRT-PCR products on $2 \%$ agarose (SeaKem, Cambrex) gels and analyzing them on AlphaImager 3400 (Alpha Innotech). The results were normalized for expression of HPRT as a control, and are shown as fold difference compared with the levels (set to 1) detected in the sample with the lowest expression. The sequences of primers used in qRT-PCR analysis are as follows: GATA-1 (sense- CAGGGCAGAATCCACAAACT, antisenseTCCTCTGCATCAACAAGCC); PU.1 (sense- TGACTACTACTCCTTCGTGG, antisense- GATAAGGGAAGCACATCCGG); C/EBP $\alpha$ (sense-

CAAGAGCCGAGATAAAGC, antisense- GTCATTGTCACTGGTCAA); JAM4 (sense-CTGTTGCTGTTGTGCCTC, antisense- TTGCCTCATCCGAACTGTA);
GAPDH (sense- TGCACCACCAACTGCTTAGC, antisense- GGCATGGACTGTGGTCATGAG).

Western blotting. The cells were lysed in $100 \mu$ of modified RIPA buffer $(150 \mathrm{mM}$ $\mathrm{NaCl}, 1 \% \mathrm{NP}-40,150 \mathrm{mM}$ Tris, $\mathrm{pH}$ 7.5, 1 mM EDTA), supplemented with protease inhibitor (Roche), PhosStop (Roche), 10 mM HEPES and 200 mM PMSF. 25-40 $\mu \mathrm{g}$ of protein from each sample was run on 12\% SDS-PAGE gels (Bio-Rad Mini ProteanTGX) and transferred to nitrocellulose membranes (Bio-Rad Trans-Blot). Prior to transfer the gels were stained with Coomassie Brilliant Blue (Bio-Rad). Rat antiGATA-1 (clone N6), rabbit anti-PU.1 (clone T-21), goat anti-JAM4 (clone M-13), goat anti-rat IgG-HRP and goat anti-rabbit IgG-HRP antibodies were purchased from Santa Cruz Biotechnology. Rabbit anti-C/EBP $\alpha$ monoclonal antibody (clone EP709Y) was purchased from Epitomics. Membranes were incubated overnight with $1: 200$ anti-GATA-1, $1: 500$ anti-PU.1, $1: 500$ anti-C/EBP $\alpha$ and $1: 500$ anti-JAM4 antibody in $5 \%$ BSA at $4{ }^{\circ} \mathrm{C}$, washed and then incubated overnight at $4{ }^{\circ} \mathrm{C}$ with $1: 10,000$ goat anti-rat IgG-HRP or goat anti-rabbit IgG-HRP secondary antibodies. Proteins were detected with TMB Membrane Peroxidase Substrate System (KPL) for detection of HRP. Human monocytic cell line U-937 (ATCC, CRL-1593.2) were used as positive controls for expression of $\mathrm{C} / \mathrm{EBP} \alpha$ protein. Membranes were stripped and incubated with rabbit anti-GAPDH antibody (Sigma-Aldrich). The levels of GATA$1, \mathrm{PU} .1, \mathrm{C} / \mathrm{EBP} \alpha, \mathrm{JAM} 4$ and GAPDH proteins in each sample were measured by densitometric scanning and analyzed with ImageJ software.

Statistical analysis. Statistical significance was determined using a two-tailed unpaired Student t-test (Prism Software, Graphpad). Data are expressed as mean \pm standard deviation (SD). The number of independent samples and experiments is provided in figure legends. Statistical significance and $\mathrm{P}$ values are indicated by asterisks and specified in figure legends. $P$ values of $\leq 0.05$ were considered statistically significant.

1. Graf, T. \& Stadtfeld, M. Heterogeneity of Embryonic and Adult Stem Cells. Cell Stem Cell 3, 480-483 (2008).

2. Raaijmakers, M. H. \& Scadden, D. T. Divided within: heterogeneity within adult stem cell pools. Cell 135, 1006-1008 (2008).

3. Hayashi, K., Lopes, S. M., Tang, F. \& Surani, M. A. Dynamic equilibrium and heterogeneity of mouse pluripotent stem cells with distinct functional and epigenetic states. Cell Stem Cell 3, 391-401 (2008).

4. Enver, T., Pera, M., Peterson, C. \& Andrews, P. W. Stem cell states, fates, and the rules of attraction. Cell Stem Cell 4, 387-397 (2009).

5. Dykstra, B. et al. Long-term propagation of distinct hematopoietic differentiation programs in vivo. Cell Stem Cell 1, 218-229 (2007).

6. Morita, Y., Ema, H. \& Nakauchi, H. Heterogeneity and hierarchy within the most primitive hematopoietic stem cell compartment. J. Exp. Med. 207, 1173-1182 (2010).

7. Beerman, I. et al. Functionally distinct hematopoietic stem cells modulate hematopoietic lineage potential during aging by a mechanism of clonal expansion. Proc. Natl Acad. Sci. USA 107, 5465-5470 (2010).

8. Hock, H. Some hematopoietic stem cells are more equal than others. J. Exp. Med. 207, 1127-1130 (2010)

9. Benveniste, P. et al. Intermediate-term hematopoietic stem cells with extended but time-limited reconstitution potential. Cell Stem Cell 6, 48-58 (2010).

10. Schroeder, T. Hematopoietic stem cell heterogeneity: subtypes, not unpredictable behavior. Cell Stem Cell 6, 203-207 (2010).

11. Benz, C. et al. Hematopoietic stem cell subtypes expand differentially during development and display distinct lymphopoietic programs. Cell Stem Cell 10, 273-283 (2012).

12. Oguro, H., Ding, L. \& Morrison, S. J. SLAM Family Markers Resolve Functionally Distinct Subpopulations of Hematopoietic Stem Cells and Multipotent Progenitors. Cell Stem Cell 13, 102-116 (2013).

13. Gekas, C. \& Graf, T. CD41 expression marks myeloid-biased adult hematopoietic stem cells and increases with age. Blood 121, 4463-4472 (2013).

14. Yamamoto, R. et al. Clonal analysis unveils self-renewing lineage-restricted progenitors generated directly from hematopoietic stem cells. Cell 154, 1112-1126 (2013).

15. Guo, G. et al. Mapping cellular hierarchy by single-cell analysis of the cell surface repertoire. Cell Stem Cell 13, 492-505 (2013).

16. Ema, H., Morita, Y. \& Suda, T. Heterogeneity and hierarchy of hematopoietic stem cells. Exp. Hematol. 42, 74-82 (2014).

17. Tian, H. et al. A reserve stem cell population in small intestine renders Lgr5positive cells dispensable. Nature 478, 255-259 (2011).

18. Sato, T., Laver, J. H. \& Ogawa, M. Reversible expression of CD34 by murine hematopoietic stem cells. Blood 94, 2548-2554 (1999).

19. Matsuoka, S. et al. CD34 expression on long-term repopulating hematopoietic stem cells changes during developmental stages. Blood 97, 419-425 (2001).

20. MacArthur, B. D. et al. Nanog-dependent feedback loops regulate murine embryonic stem cell heterogeneity. Nat. Cell Biol. 14, 1139-1147 (2012).

21. Hanna, J. et al. Metastable pluripotent states in NOD-mouse-derived ESCs. Cell Stem Cell 4, 513-524 (2009).

22. Wilson, A. et al. Hematopoietic stem cells reversibly switch from dormancy to self-renewal during homeostasis and repair. Cell 135, 1118-1129 (2008). 
23. Challen, G. A., Boles, N. C., Chambers, S. M. \& Goodell, M. A. Distinct hematopoietic stem cell subtypes are differentially regulated by TGF- $\beta 1$. Cell Stem Cell 6, 265-278 (2010).

24. Gupta, P. B. et al. Stochastic state transitions give rise to phenotypic equilibrium in populations of cancer cells. Cell 146, 633-644 (2011).

25. Tonge, P. D., Shigeta, M., Schroeder, T. \& Andrews, P. W. Functionally defined substates within the human embryonic stem cell compartment. Stem Cell Res. 7, 145-153 (2011).

26. van Es, J. H. et al. Dll1 + secretory progenitor cells revert to stem cells upon crypt damage. Nat. Cell Biol. 14, 1099-1104 (2012).

27. Schwitalla, S. et al. Intestinal Tumorigenesis Initiated by Dedifferentiation and Acquisition of Stem-Cell-like Properties. Cell 152, 25-38 (2013).

28. Blau, H. M., Brazelton, T. R. \& Weimann, J. M. The evolving concept of a stem cell: entity or function. Cell 105, 829-841 (2001).

29. Zipori, D. The nature of stem cells: state rather than entity. Nat. Rev. Genet. 5, 873-878 (2004).

30. Tsai, S., Bartelmez, S., Sitnicka, E. \& Collins, S. Lymphohematopoietic progenitors immortalized by a retroviral vector harboring a dominant-negative retinoic acid receptor can recapitulate lymphoid, myeloid, and erythroid development. Genes Dev. 8, 2831-2841 (1994).

31. Ye, Z. J., Kluger, Y., Lian, Z. \& Weissman, S. M. Two types of precursor cells in a multipotential hematopoietic cell line. Proc. Natl Acad. Sci. USA 102, 18461-6 (2005).

32. Chang, H. H., Hemberg, M., Barahona, M., Ingber, D. E. \& Huang, S. Transcriptome-wide noise controls lineage choice in mammalian progenitor cells. Nature 453, 544-547 (2008).

33. Ye, Z. J. et al. Complex interactions in EML cell stimulation by stem cell factor and IL-3. Proc. Natl Acad. Sci. USA 108, 4882-7 (2011).

34. Pina, C. et al. Inferring rules of lineage commitment in haematopoiesis. Nat. Cell Biol. 14, 287-294 (2012)

35. Kirito, K., Fox, N. \& Kaushansky, K. Thrombopoietin stimulates Hoxb4 expression: an explanation for the favorable effects of TPO on hematopoietic stem cells. Blood 102, 3172-3178 (2003).

36. Si, J. \& Collins, S. J. IL-3-induced enhancement of retinoic acid receptor activity is mediated through Stat5, which physically associates with retinoic acid receptors in an IL-3-dependent manner. Blood 100, 4401-4409 (2003).

37. Zayas, J., Spassov, D. S., Nachtman, R. G. \& Jurecic, R. Hematopoietic stem cells and multipotent progenitors express new truncated intracellular form of c-kit receptor. Stem Cells Dev. 17, 343-353 (2008).

38. Jing, X., Infante, J., Nachtman, R. G. \& Jurecic, R. E3 ligase FLRF (Rnf41) regulates differentiation of hematopoietic progenitors by governing steady-state levels of cytokine and retinoic acid receptors. Exp. Hematol. 36, 1110-1120 (2008).

39. Kutleša, S., Zayas, J., Valle, A., Levy, R. B. \& Jurecic, R. T cell differentiation of multipotent hematopoietic cell line EML in the OP9-DL1 co-culture system. Exp. Hematol. 37, 909-923 (2009).

40. Lee, H. M., Zhang, H., Schulz, V., Tuck, D. P. \& Forget, B. G. Downstream targets of HOXB4 in a cell line model of primitive hematopoietic progenitor cells. Blood 116, 720-730 (2010)

41. Wu, J. Q. et al. Tcf7 is an important regulator of the switch of self-renewal and differentiation in a multipotential hematopoietic cell line. PLoS Genet. 8 e1002565 (2012).

42. Osawa, M., Hanada, K., Hamada, H. \& Nakauchi, H. Long-term lymphohematopoietic reconstitution by a single CD34-low/negative hematopoietic stem cell. Science 273, 242-245 (1996).

43. Adolfsson, J. et al. Upregulation of Flt3 expression within the bone marrow Lin $(-) \mathrm{Scal}(+) \mathrm{c}$-kit $(+)$ stem cell compartment is accompanied by loss of self-renewal capacity. Immunity 15, 659-669 (2001).

44. Yang, L. et al. Identification of Lin $(-)$ Sca1(+)kit(+)CD34(+)Flt3- short-term hematopoietic stem cells capable of rapidly reconstituting and rescuing myeloablated transplant recipients. Blood 105, 2717-2723 (2005).

45. Hattori, K. et al. Placental growth factor reconstitutes hematopoiesis by recruiting VEGFR1 $(+)$ stem cells from bone-marrow microenvironment. Nat. Med. 8 841-849 (2002).

46. Gerber, H. P. et al. VEGF regulates haematopoietic stem cell survival by an internal autocrine loop mechanism. Nature 417, 954-958 (2002).

47. Wiesmann, A. et al. Expression of CD27 on murine hematopoietic stem and progenitor cells. Immunity 12, 193-199 (2000).

48. Balazs, A. B., Fabian, A. J., Esmon, C. T. \& Mulligan, R. C. Endothelial protein C receptor (CD201) explicitly identifies hematopoietic stem cells in murine bone marrow. Blood 107, 2317-2321 (2005).
49. Wagers, A. J. \& Weissman, I. L. Differential expression of alpha2 integrin separates long-term and short-term reconstituting Lin-/loThy1.1(lo)c-kit+ Sca1+ hematopoietic stem cells. Stem Cells 24, 1087-1094 (2006).

50. Park, I. K. et al. Differential gene expression profiling of adult murine hematopoietic stem cells. Blood 99, 488-498 (2002).

51. Zhong, J. F. et al. Gene expression profile of murine long-term reconstituting vs. short-term reconstituting hematopoietic stem cells. Proc. Natl Acad. Sci. USA 102, 2448-2453 (2005).

52. Chambers, S. M. et al. Hematopoietic fingerprints: an expression database of stem cells and their progeny. Cell Stem Cell 1, 578-591 (2007).

53. Arinobu, Y. et al. Reciprocal activation of GATA-1 and PU.1 marks initial specification of hematopoietic stem cells into myeloerythroid and myelolymphoid lineages. Cell Stem Cell 1, 416-247 (2007).

54. Wontakal, S. N. et al. A core erythroid transcriptional network is repressed by a master regulator of myelo-lymphoid differentiation. Proc. Natl Acad. Sci. USA 109, 3832-3837 (2012)

55. Suh, H. C., Gooya, J., Renn, K., Friedman, A. D., Johnson, P. F. \& Keller, J. R. C/ EBPalpha determines hematopoietic cell fate in multipotential progenitor cells by inhibiting erythroid differentiation and inducing myeloid differentiation. Blood 107, 4308-4316 (2006)

56. Wölfler, A. et al. Lineage-instructive function of $\mathrm{C} / \mathrm{EBP} \alpha$ in multipotent hematopoietic cells and early thymic progenitors. Blood 116, 4116-4125 (2010).

57. Hasemann, M. S. et al. $\mathrm{C} / \mathrm{EBP} \alpha$ is required for long-term self-renewal and lineage priming of hematopoietic stem cells and for the maintenance of epigenetic configurations in multipotent progenitors. PLoS Genet. 10, e1004079 (2014).

58. Nagamatsu, G. et al. A CTX family cell adhesion molecule, JAM4, is expressed in stem cell and progenitor cell populations of both male germ cell and hematopoietic cell lineages. Mol. Cell Biol. 26, 8498-8506 (2006)

59. Kunisaki, Y. \& Frenette, P. S. The secrets of the bone marrow niche: Enigmatic niche brings challenge for HSC expansion. Nat. Med. 18, 864-865 (2012).

60. Lu, R., Neff, N. F., Quake, S. R. \& Weissman, I. L. Tracking single hematopoietic stem cells in vivo using high-throughput sequencing in conjunction with viral genetic barcoding. Nat. Biotechnol. 29, 928-33 (2011).

\section{Acknowledgments}

We thank Dr. Collins (Fred Hutchinson Cancer Research Center, Seattle, WA) for kindly providing EML and BHK/MKL cell lines; Ash Anand, Eileen L. Welch, Sarah Van Liew and Jessica Gonzalez for technical assistance; and the staff of the Sylvester Cancer Center Flow Cytometry Core Facility for expert help with cell analysis and sorting. We also extend our sincere thanks to our colleague Dr. Becky Adkins for critical reading of the manuscript. This research was supported by the National Institutes of Health, American Cancer Society and Children's Leukemia Research Association, Inc.

\section{Author contributions}

W.W., J.Z. and R.J. developed the concept and designed experiments. W.W.W. and R.J. wrote the manuscript. R.J. supervised the project. W.W., J.Z., R.P. and J.G. performed the experiments.

\section{Additional information}

Supplementary information accompanies this paper at http://www.nature.com/ scientificreports

Competing financial interests: The authors declare no competing financial interests.

How to cite this article: Weston, W., Zayas, J., Perez, R., George, J. \& Jurecic, R. Dynamic equilibrium of heterogeneous and interconvertible multipotent hematopoietic cell subsets. Sci. Rep. 4, 5199; DOI:10.1038/srep05199 (2014).

This work is licensed under a Creative Commons Attribution-NonCommercialNoDerivs 3.0 Unported License. The images in this article are included in the article's Creative Commons license, unless indicated otherwise in the image credit; if the image is not included under the Creative Commons license, users will need to obtain permission from the license holder in order to reproduce the image. To view a copy of this license, visit http://creativecommons.org/licenses/by-nc-nd/3.0/ 